\title{
Copyright
}

by

Shankar Venkataraman

2008 
The Dissertation Committee for Shankar Venkataraman Certifies that this is the approved version of the following dissertation:

\section{The Joint Impact of Commitment to Disclosure and Prior Forecast Accuracy on Managers' Forecasting Credibility}

\section{Committee:}

Lisa L. Koonce, Co-Supervisor

D. Eric Hirst, Co-Supervisor

Keith C. Brown

Steven J. Kachelmeier

Arthur B. Markman 
The Joint Impact of Commitment to Disclosure and Prior Forecast Accuracy on Managers' Forecasting Credibility

\author{
by \\ Shankar Venkataraman, B.Com., P.G.D.M., M.I.M.
}

\author{
Dissertation \\ Presented to the Faculty of the Graduate School of \\ The University of Texas at Austin \\ in Partial Fulfillment \\ of the Requirements \\ for the Degree of \\ Doctor of Philosophy
}

The University of Texas at Austin

August, 2008 


\section{Acknowledgements}

I thank my dissertation co-chairs — Eric Hirst and Lisa Koonce for their guidance and support throughout the doctoral program. I also thank Steve Kachelmeier, but for whose early encouragement, I would not have made it this far in the program. I thank my other committee members - Keith Brown and Art Markman for their useful suggestions.

I appreciate the assistance and friendship provided by my fellow doctoral students at the University of Texas at Austin. Every single doctoral student in the accounting program, at some time or the other, has contributed to this dissertation by providing helpful comments on the experimental materials and / or early versions of the paper. This dissertation benefited greatly from the comments of seminar participants at the University of Alberta, Cornell University, Georgia Tech University, University of Illinois, Nanyang Business School, National University of Singapore, and the University of Texas. I gratefully acknowledge the financial support from the Eugene and Dora Bonham Memorial Fund and the Department of Accounting at the University of Texas at Austin.

I am also thankful to Vijaysree Venkataraman, Subash Pereira, Balaji Koka, and Rangaraj Ramanujam, who provided counsel and encouragement, whenever needed. I thank my wife Malavika and my daughter Aditi for their unwavering love, for believing in me, and for sharing all the highs and lows of the dissertation experience. Above all, I thank my parents Arunachalam Venkataraman and Lakshmi Venkataraman for their unconditional love and for placing their children's education above their personal comfort at all times. To them, I dedicate this dissertation. 


\title{
The Joint Impact of Commitment to Disclosure and Prior Forecast Accuracy on Managers' Forecasting Credibility
}

\author{
Publication No. \\ Shankar Venkataraman, Ph.D. \\ The University of Texas at Austin, 2008
}

Supervisors: Lisa L. Koonce and D. Eric Hirst

\begin{abstract}
Although managers rate concerns about being seen as committed disclosers as an important consideration in their voluntary disclosure decisions, prior research has paid limited attention to how investors view commitment to disclosure. This study experimentally tests two competing perspectives relating to how managers' commitment to disclosure and prior forecast accuracy jointly influence managers' forecasting credibility. The first perspective (the normative perspective) draws on economic theory and the second perspective (the omission bias perspective) draws on theory from psychology. The normative perspective suggests that commitment to disclosure and prior forecast accuracy will independently influence managers' forecasting credibility. In contrast, the omission bias literature suggests that the influence of commitment to disclosure on managers' forecasting credibility depends on managers' prior forecast accuracy. In other words, the normative perspective suggests two main effects, whereas the omission bias perspective suggests a commitment to disclosure $\times$ accuracy interaction. To test the competing predictions relating to the joint impact of
\end{abstract}


commitment to disclosure and prior forecast accuracy on managers' forecasting credibility, I conduct an experiment. Results of this experiment support the omission bias perspective. Participants in the role of investors rate more (less) committed managers as more (less) credible, but only when they are also accurate. When managers are inaccurate, however, this relationship reverses. That is, more committed managers are viewed as less credible relative to their less committed peers. These results suggest that managers' concerns about commitment to disclosure are indeed valid, but only when they are accurate. When managers are less accurate, commitment to disclosure hurts, rather than helps, managers' credibility. Participants' valuation judgments as well as their judgments relating to a current disclosure are positively associated with their judgments of managers' forecasting credibility, suggesting that their assessment of managers' credibility may have significant valuation consequences. This study contributes to the voluntary disclosure literature and has implications for managers who provide earnings forecasts and for investors who use these forecasts in their investment decisions. 


\section{Table of Contents}

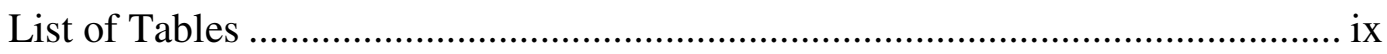

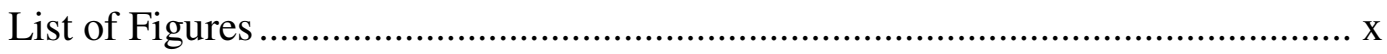

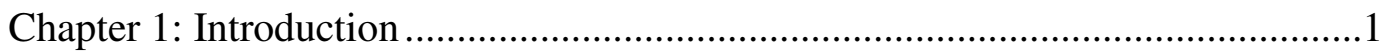

Chapter 2: A Framework to Evaluate Management Earnings Forecasts ..................7

What are Management Earnings Forecasts? ....................................................

Why are Management Earnings Forecasts Important? ..................................

Management Earnings Forecasts: A Framework ………...............................8

Chapter 3: The Joint Impact of Commitment to Disclosure and Prior Forecast

Accuracy on Managers' Forecasting Credibility .............................................13

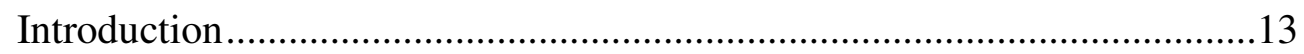

Managers' Forecasting Credibility ..........................................................14

What is Managers' Forecasting Credibility? .........................................14

Why is Managers' Forecasting Credibility Important? ........................14

Commitment to Disclosure: Main Effects .....................................................15

Prior forecast accuracy: Main Effects........................................................19

The Joint Impact of Commitment to Disclosure and Prior Forecast

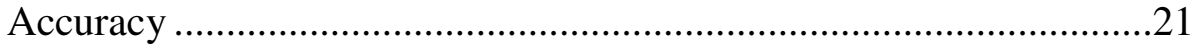

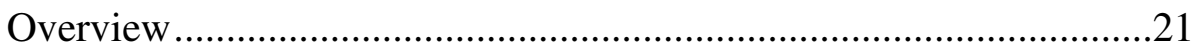

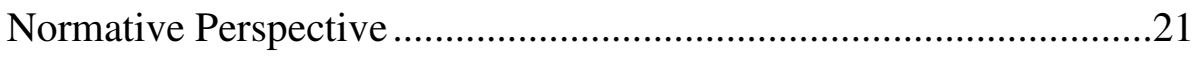

Omission Bias Perspective...............................................................24

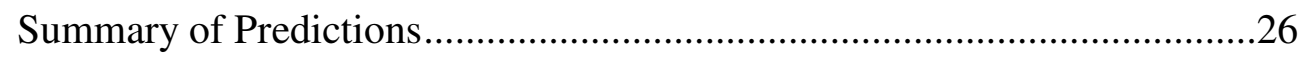

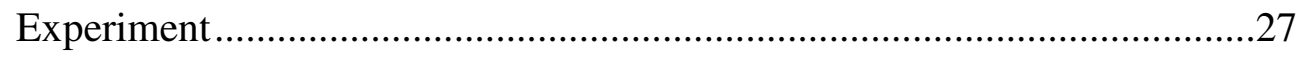

Design and Participants......................................................................27

Materials, Manipulations, and Questions............................................29

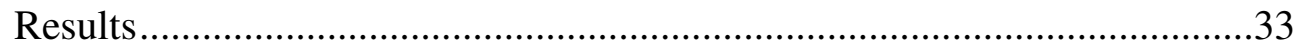

Manipulation and Other Checks .........................................................33

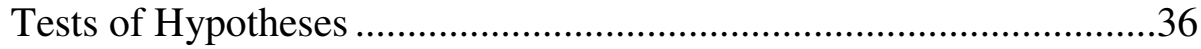

Judgments of Managers' Trustworthiness ......................................37

vii 
Judgments of Managers' Forecasting Competence ...................38

Judgments of Managers' Forecasting Credibility ......................40

Other Judgments .................................................................41

Additional Analyses: Structural Equation Model .....................44

Chapter 4: Conclusion...........................................................................64

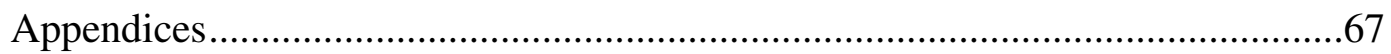

Appendix A: Commitment To Disclosure: Illustration .............................68

Appendix B: Experimental Materials ................................................... 71

Appendix C: Pre-Manipulation Questions.............................................74

Appendix D: Manipulations.............................................................. 77

Appendix E: Post-Manipulation Questions .............................................82

Appendix F: Current Earnings Forecast ..................................................85

Appendix G: Process-Related Questions ..............................................8

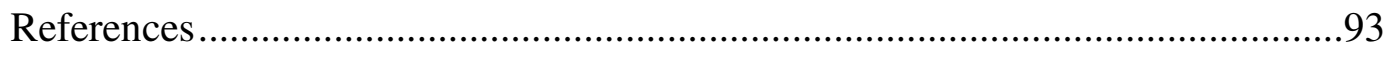

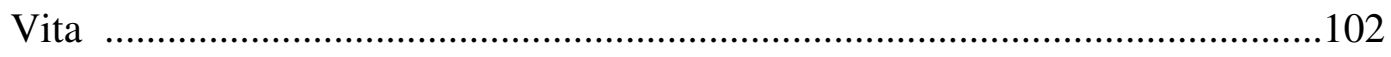




\section{List of Tables}

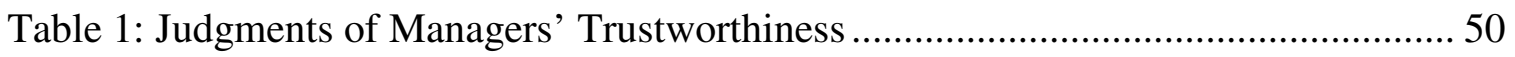

Table 2: Judgments of Managers' Forecasting Competence ....................................... 52

Table 3: Judgments of Managers' Forecasting Credibility .......................................... 54

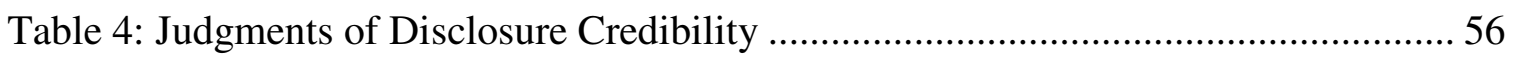

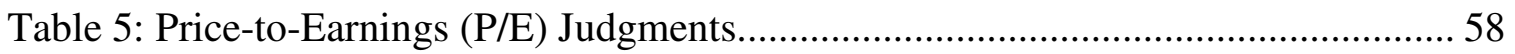




\section{List of Figures}

Figure 1: A Framework to Study Management Earnings Forecasts (Hirst et al. 2008)... 12

Figure 2: Managers' Forecasting Credibility: Normative Versus Omission Bias

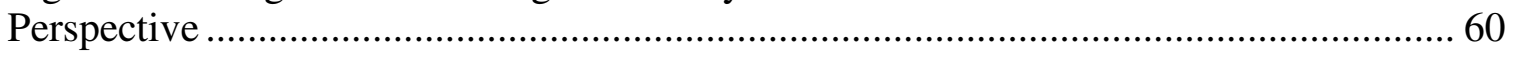

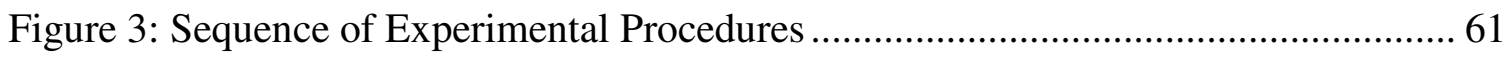

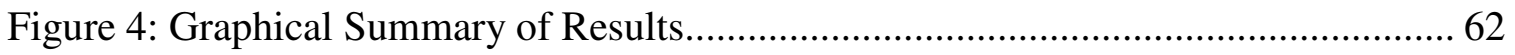

Figure 5: Structural Equation Model: Commitment to Disclosure and Perceptions of Norm-Consistency 


\section{Chapter 1: Introduction}

Managers who choose to provide earnings forecasts face a choice. Should they provide such forecasts frequently and predictably in an effort to be viewed as more committed disclosers or can they provide forecasts in some periods and remain silent in others and thus risk being viewed as less committed disclosers? Managers maintain that investors value commitment to disclosure and, therefore, being seen as more committed to disclosure is important (Graham et al. 2005). Consistent with this position, prior research shows that less committed disclosers pay more for their capital relative to more committed disclosers (Brown et al. 2004) and are more likely to lose analyst coverage (Houston et al. 2006). Yet, prior research also shows that managers are selective about the periods in which they provide earnings forecasts (Cotter et al. 2006). One reason for this selectivity could be that managers may be inclined to forecast only when they believe that they will be accurate (Waymire 1985). This study investigates the joint impact of commitment to disclosure and prior forecast accuracy on managers' forecasting credibility. Specifically, it examines whether there are conditions when commitment to disclosure may hurt, instead of help, managers' forecasting credibility. ${ }^{1}$

Understanding the credibility consequences of commitment to disclosure is important for at least two reasons. First, economic theory posits that proprietary costs and litigation concerns are two important factors that influence voluntary disclosures (Verrecchia 2001, Skinner 1994). Yet, managers rank concerns about setting a disclosure precedent that cannot be maintained as more important than both proprietary cost and

\footnotetext{
${ }^{1}$ Following prior research, I define managers' forecasting credibility as investors' beliefs about managers' trustworthiness and forecasting competence (Mercer 2005).
} 
litigation cost concerns in influencing their disclosure decisions (Graham et al. 2005). ${ }^{2}$ In other words, managers appear to be apprehensive about being viewed as less committed disclosers because periods of silence punctuated by periods of disclosure could be interpreted negatively by investors. Thus, understanding the credibility consequences of being more (or less) committed to disclosure under varying levels of accuracy is important to managers who determine voluntary disclosure policies.

Second, the results of this study are important to researchers interested in improving their understanding of the factors that influence managers' reporting credibility. Prior research has relied primarily on forecast-accuracy based measures to infer managers' credibility (Williams 1996, Atiase et al. 2006), where accuracy is defined as the difference between reported earnings and managers' earnings forecasts. In this study, I argue that commitment to disclosure is another important factor that influences managers' reporting credibility, both individually and jointly with prior forecast accuracy. Drawing on theories from economics and psychology, I generate and test competing hypotheses about how commitment to disclosure and accuracy jointly influence managers' reporting credibility.

To test the joint impact of commitment to disclosure and prior forecasting accuracy on managers' forecasting credibility, I conduct a $2 \times 2$ between-subjects experiment where I vary managers' commitment to disclosure (more versus less committed) and prior forecast accuracy (high versus low). Participants in the role of

\footnotetext{
${ }^{2}$ Graham et al. (2005) ask their survey respondents to rank the reasons for limiting their voluntary financial communications. The study provides several reasons and asked respondents to indicate the extent to which they agreed with these reasons. Seventy percent of respondents agreed (or strongly agreed) that "avoid(ing) setting a disclosure precedent that may be difficult to continue", was a factor influencing their voluntary disclosure decisions. Fifty nine percent of respondents agreed (or strongly agreed) that proprietary concerns were a factor. Forty six percent agreed (or strongly agreed) that litigation concerns were a factor influencing their voluntary disclosure decisions. These responses suggest that managers' concern about setting a disclosure precedent that cannot be maintained is an important factor that influences their voluntary disclosure decisions.
} 
potential investors provide their assessment of managers' trustworthiness, managers' forecasting competence, and manager's forecasting credibility (the primary dependent variable) based on experimental materials relating to a hypothetical company. I also obtain participants' valuation judgments for this company to ensure that managers' forecasting credibility is associated with substantive economic consequences.

My experiment tests two competing perspectives about the joint impact of commitment to disclosure and forecast accuracy on managers' forecasting credibility. The first perspective (hereafter, the normative perspective) draws on economic theory (Dye 2001, Verrecchia 2001, Stocken 2000) which suggests that managers' reporting credibility will be jointly influenced by commitment to disclosure and prior forecast accuracy. The implication of this perspective is that both commitment to disclosure and prior forecast accuracy exert independent main effects on managers' forecasting credibility. In other words, the effect of commitment to disclosure and prior forecast accuracy on managers' forecasting credibility is additive.

The second perspective draws on the omission bias literature from psychology and posits that stronger inferences are made about an individual based on action rather than inaction (Baron and Ritov 1994, Spranca et al. 1991). To the extent that more committed disclosers are viewed as taking more actions relative to their less committed peers, the omission bias perspective would suggest that investors will make stronger inferences about managers' forecasting credibility when managers are more committed to disclosure than when they are less committed to disclosure. Specifically, when managers are more committed to disclosure, investors will distinguish between more accurate forecasters and less accurate forecasters (with respect to their forecasting credibility). In contrast, when managers are less committed to disclosure, although investors may still 
distinguish between more and less accurate forecasters, the distinction is likely to be weaker.

Although both perspectives suggest that commitment to disclosure and forecast accuracy will jointly influence investors' assessment of managers' forecasting credibility, they differ with respect to whether the two factors interact. The normative perspective suggests that the two factors are additive. That is, holding constant accuracy, more commitment to disclosure always increases managers' forecasting credibility. In contrast, the omission bias perspective suggests that managers will be better off (with respect to forecasting credibility) by being more committed disclosers only when prior forecast accuracy is high and worse off when prior forecast accuracy is low. In other words, the omission bias perspective suggests a commitment $\times$ accuracy interaction effect on managers' forecasting credibility.

Using an experiment to study the joint impact of commitment to disclosure and prior forecast accuracy is advantageous for several reasons. First, over time, companies change forecast form and other attributes of their forecasts (e.g., forecast content), rendering longitudinal comparisons difficult (King et al. 1990, Hirst et al. 1999). By holding constant such forecast attributes, an experiment allows me to focus on the treatment of interest. Second, prior research documents that forecast accuracy is likely to be confounded with bias in a natural setting. For instance, Chen (2004) finds that quarterly earnings forecasts are systematically pessimistically-biased. ${ }^{3}$ An experiment allows me to hold constant the forecast bias and focus on accuracy. Third, an experiment allows me to directly measure participants' perceptions relating to commitment to

\footnotetext{
${ }^{3}$ For the period 1994-2003, Chen (2004) finds that the likelihood of missing quarterly forecasts (16\%) is substantially lower than the likelihood of beating forecasts (39\%), suggesting that quarterly forecasts are, on average, pessimistically biased.
} 
disclosure, thereby, potentially improving our understanding of the underlying mechanisms via which commitment to disclosure influences credibility.

I find support for the omission bias perspective on how commitment to disclosure and prior forecast accuracy jointly influence investors' judgments of managers' forecasting credibility. Specifically, more committed forecasters are judged as more credible relative to less committed forecasters, but only when forecast accuracy is high. This relationship, however, reverses when prior forecast accuracy is low - more committed forecasters are judged to be less credible relative to less committed forecasters.

Results of additional tests provide some evidence on the mechanism underlying this result. The omission bias literature proposes two alternative mechanisms by which acts of commission lead to stronger judgments relative to acts of omission. The first mechanism posits that acts of commission are seen as more deliberate decisions relative to acts of omission, and it is this decision versus non-decision dichotomy that makes people react more strongly to acts of commission (Baron and Ritov 1994, Niedermayer and Chapman 2001, Kordes-de Vaal 1996). A second explanation suggests that in contexts where the default option or the norm is inaction, omissions will be viewed as consistent with the norm whereas commissions will be viewed as inconsistent with the norm (Prentice and Koehler 2003). ${ }^{4}$ Both negative and positive outcomes associated with norm-inconsistent behavior elicit stronger reactions compared to identical outcomes resulting from norm-inconsistent behavior. According to this perspective, it is not the decision versus non-decision dichotomy, but the norm-consistent versus norminconsistent dichotomy that drives the omission bias.

\footnotetext{
${ }^{4}$ Baron and Ritov (1994) also posit and test norm-based explanations for the omission bias, but they find only limited support for a norm-based explanation of the omission bias.
} 
My results suggest that participants distinguish between more and less committed forecasters, not based on whether or not commitment to disclosure corresponds to a decision, but based on whether commitment to disclosure is viewed as norm-consistent or inconsistent behavior. Participants' judgments of managers' credibility suggest that behavior that is above and beyond the norm (high commitment to disclosure) leads to stronger reactions compared to behavior that is in line with the norm (low commitment to disclosure). I also discuss the implication of these findings for the voluntary disclosure and the omission bias literatures.

The rest of this dissertation is organized as follows. Chapter 2 provides an introduction to management earnings forecasts and discusses a framework to evaluate management earnings forecasts. More specifically, it explains the elements of the framework that form the focus of this study. Chapter 3 outlines how commitment to disclosure and prior forecast accuracy influence perceptions of trustworthiness and competence, both individually and jointly. Drawing on an economic theory as well as on theory from psychology, this section generates competing predictions about the joint impact of commitment to disclosure and prior forecast accuracy on managers' forecast credibility. Chapter 3 also describes an experiment designed to test these competing predictions and discusses the results of the experiment. Chapter 4 concludes with a discussion of the study's findings. 


\section{Chapter 2: A Framework to Evaluate Management Earnings Forecasts}

\section{WHAT ARE MANAGEMENT EARNINGS FORECASTS?}

Management earnings forecasts are voluntary managerial disclosures predicting earnings prior to the expected reporting date (King et al. 1990). The term earnings guidance is often used synonymously with earnings forecasts, both in the popular press (Zuckerman 2005) and in the academic literature (Atiase et al. 2005, Hutton 2005). Although earnings forecasts are commonly issued well in advance of quarterly and annual earnings releases, they are sometimes provided after the accounting period has ended but before the earnings are announced. ${ }^{5}$ These latter forecasts are typically referred to as earnings preannouncements. ${ }^{6}$ When management forecasts indicate substantial shortfall from expected earnings, they are commonly termed earnings warnings (Kasznik and Lev 1995).

\section{WHY ARE MANAGEMENT EARNINGS FORECASTS IMPORTANT?}

Management earnings forecasts are important because they are associated with several market outcomes that managers care about. For example, earnings forecasts can be used to mitigate litigation concerns (Skinner 1994), influence managers' reputation for transparent and accurate reporting (Hutton and Stocken 2007), influence stock prices (Pownall et al. 1993), analysts' forecasts (Baginski and Hassell 1990), and bid-ask spreads (Coller and Yohn 1997). In addition, management earnings forecasts represent one of the most direct means by which managers can influence the markets' earnings

\footnotetext{
${ }^{5}$ Earnings guidance represents any manager-provided information that guides outsiders in their assessment of a firm's future earnings, both directly and indirectly (Miller 2002). Thus, earnings guidance might include, but need not be limited to, earnings forecasts. For instance, a firm's comments on its prospects in a new product market might be construed as indirect earnings guidance.

${ }^{6}$ Even though preannouncements are technically earnings forecasts, most of the literature treats them as early earnings announcements rather than late earnings forecasts.
} 
expectations. Particularly after Regulation Fair Disclosure (Reg. FD), managers can no longer selectively disseminate their expectations about earnings to analysts or other select individuals and thus expect to influence the markets' earnings expectations. Arguably, Reg. FD has made management earnings forecasts even more relevant to managers as a tool to set and manage market earnings expectations. Managers should care about setting (or recalibrating) market earnings expectations because the adverse consequences of failing to meet market earnings expectations are well documented (Matsumoto 2002, Brown and Caylor 2005). Overall, the empirical evidence clearly shows that management earnings forecasts are an important voluntary disclosure and are associated with significant economic consequences.

\section{MANAGEMENT EARNINGS FORECASTS: A FRAMEWORK}

In a survey of the management earnings forecasts literature, Hirst et al. (2008) provide a framework in which to review management earnings forecasts. This framework categorizes earnings forecasts as having three components - antecedents, characteristics, and consequences - that roughly correspond to the timeline associated with an earnings forecast. ${ }^{7}$ They note that much of the prior research on management earnings forecasts focuses on how one forecast antecedent or characteristic influences forecast consequences, and does not study potential interactions among the three components of the framework. In this study, I address their call to study potential interactions among components of this framework. Specifically, I examine the joint impact of impact of two forecast antecedents - managers' commitment to disclosure and prior forecasting accuracy on managers' forecasting credibility - a consequence in the framework. I first

\footnotetext{
${ }^{7}$ The discussion relating to the framework presented here is a condensed version of the discussion in Hirst et al. (2008).
} 
provide a brief description of the framework and then explain how the current study contributes to the management earnings forecast literature.

Figure 1 provides a pictorial representation of a framework provided by Hirst et al. (2008) to analyze management earnings forecasts. Antecedents are precursors to the actual forecast decision. Because earnings forecasts are voluntary disclosures, the first question confronting managers is whether to issue a forecast. The answer to this question is shaped by a combination of the environment faced by the firm and firm-specific characteristics. Hirst et al. (2008) classify antecedents into two broad categories: (1) forecast environment - that is, features of the legal and regulatory environment and features of the analyst and investor environment, and (2) forecaster characteristics - that is, information asymmetry, pre-commitment to disclosure, firm-specific litigation, managerial incentives, prior forecasting behavior, and proprietary costs. Firms often have little or no control over certain antecedents in the short term, although they can influence some of those antecedents in the longer term. For example, a firm's prior forecasting accuracy is an antecedent. A reputation for accuracy is normally built over an extended time and is generally not quickly changeable.

Having chosen to issue an earnings forecast, the manager then faces a broad array of choices regarding the attributes of that forecast. These choices involve, for example, the form of the forecast (e.g., point, range, qualitative, etc.), the horizon (e.g., quarterly versus annual), and the information to accompany the forecast (e.g., the presence or absence of attributions). These choices are termed forecast characteristics because they are attributes associated with the forecast.

The third component of the framework — forecast consequences - captures events and reactions that occur after the forecast is issued, such as the stock market reaction to the forecasted earnings information. Not surprisingly, these consequences are 
a function of the antecedents and forecast characteristics. For example, management forecasts lead to greater earnings forecast revisions by analysts - a consequence, when they originate from firms with high prior forecast accuracy — an antecedent (Williams 1996). This study examines two forecast antecedents - managers' commitment to disclosure and prior forecast accuracy, and examines how these antecedents jointly impact managers' forecasting credibility — a consequence.

This study makes several contributions to the voluntary disclosure literature. First, it tests competing hypotheses based on theory from economics and psychology about how commitment to disclosure and prior forecast accuracy jointly influence managers' forecasting credibility. Second, this study adds to the literature on how investors react to managers' historical disclosure behavior. Prior studies document an inverse relationship between commitment to disclosure and cost of capital (Leuz and Verrecchia 2002, Botosan and Harris 2000). These studies, however, are not designed to examine the mechanism by which these valuation consequences arise. In this study, I show that the valuation consequences reported in these earlier studies may be mediated by investors' perceptions of managers' credibility - the primary dependent variable in this study.

Finally, this study also has implications for managers and investors. The study corroborates managers' claims about the value that investors place on commitment to disclosure. Consistent with managers' claims, more committed disclosers are, indeed, seen as more credible relative to less committed disclosers, but only when they are generally accurate with respect to their forecasts. When managers are inaccurate, commitment to disclosure hurts, rather than helps their credibility. From investors' standpoint, given that the results support the predictions of the omission bias literature, it appears that investors tend to focus more on outcomes of managers' actions or commissions (disclosures) rather than the strategic implications of managers' inactions or 
omissions (non-disclosures). Although this study cannot comment on whether or not such behavior is sub optimal, investors may wish to more carefully consider the reasons for managers' disclosures as well as those for managers' non-disclosures. 
Figure 1: A Framework to Study Management Earnings Forecasts (Hirst et al. 2008)

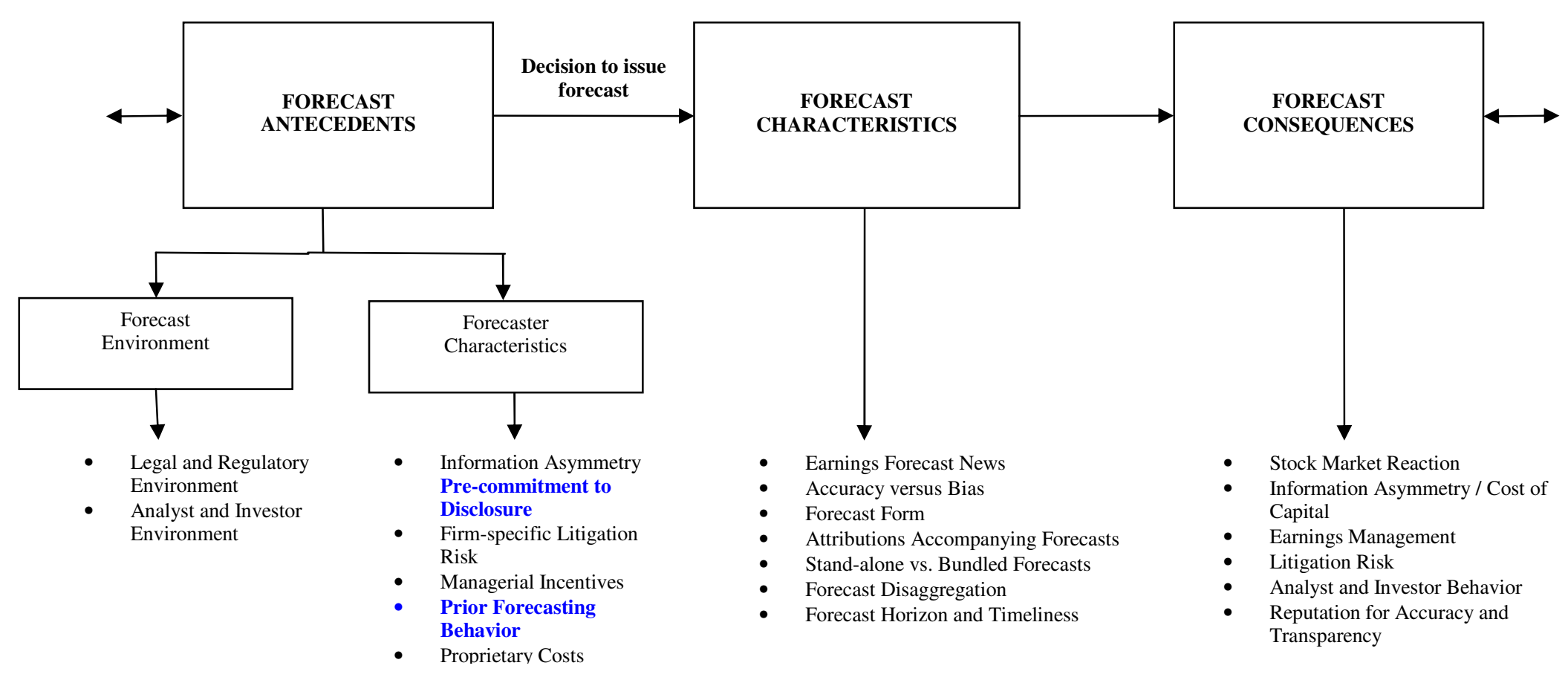




\section{Chapter 3: The Joint Impact of Commitment to Disclosure and Prior Forecast Accuracy on Managers' Forecasting Credibility}

\section{INTRODUCTION}

In this chapter, I draw on the framework described in the previous chapter and test whether and how two antecedents from the framework jointly impact a consequence described in the framework. Specifically, I examine how commitment to disclosure and prior forecast accuracy (two antecedents) jointly impact managers' forecasting credibility (a consequence), holding constant other forecast characteristics.

This chapter proceeds as follows. First, I define managers' forecasting credibility and outline why it is important. Second, I posit how commitment to disclosure and prior forecast accuracy independently and jointly impact managers' forecasting credibility. I draw on economic theory as well as theory from psychology to motivate competing predictions relating to the joint impact of commitment to disclosure and prior forecast accuracy on managers' forecasting credibility. Specifically, I draw on the voluntary disclosure literature from economics and the omission bias literature from psychology to generate competing interaction predictions. I then describe an experiment that tests these competing predictions as well as the underlying mechanisms by which commitment to disclosure and prior forecast accuracy potentially impact managers' forecasting credibility. In this experiment, I vary managers' commitment to disclosure (more versus less committed) and prior forecast accuracy (high versus low) and measure participants' perceptions of managers' forecasting credibility as well as managers' trustworthiness and

forecasting competence. Finally, I present the results of the experiment and describe the theoretical and practical implications of my results. 


\section{MANAgers' Forecasting CredibiLity}

\section{What is Managers' Forecasting Credibility?}

Drawing on prior research (Fogg and Tseng 1999, Mercer 2005), I define managers' forecasting credibility as investors' beliefs in managers' trustworthiness and forecasting competence. By trustworthiness, I mean investors' belief that managers will act with integrity when providing earnings forecasts. For example, if a company consistently provides pessimistically-biased earnings forecasts and reported earnings always exceeds forecasts, investors may question the trustworthiness of managers who provide such forecasts. By forecasting competence, I mean investors' assessment of the manager's ability with respect to forecasting earnings. Managers who have a record of consistently meeting their earnings forecasts are likely be viewed as more competent. Perceptions of trustworthiness and competence, in turn, positively influence managers' forecasting credibility by reducing uncertainty and, therefore, the risk associated with an investment.

\section{Why is Managers' Forecasting Credibility Important?}

Managers' forecasting credibility is important because investors' assessment of the credibility of a specific disclosure (disclosure credibility) is positively influenced by managers' credibility (Mercer 2004). By definition, credible disclosures are more believable and managers who want their financial disclosures to have an impact seek more credible disclosures. Prior research shows that the market reaction to management earnings forecasts is a function of the information content of the forecast and the believability (credibility) of the forecast (Jennings 1987). ${ }^{8}$

\footnotetext{
8 "The reaction of investors' beliefs to the release of a manager's earnings forecast depends on the unexpected component (surprise) of the forecast and its believability. Two management projections with the same surprise (relative to contemporaneous investor beliefs) but with different levels of believability will elicit different responses from investors." (Jennings 1987, p.91)
} 
Prior research using proxies for managers' credibility suggests that market reactions to managers' financial disclosures is conditioned on managers' credibility. For example, research using managers' prior forecasting accuracy as a proxy for managers' credibility finds that analysts update their earnings forecasts to be more in line with that of managers' when managers have been accurate in the past (Williams 1996, Atiase et al. 2006). More generally, prior research finds a positive relationship between analysts' ratings of firm disclosures and analyst coverage (Healy et al. 1999) and negative relation between analysts' ratings of firms' disclosures and bid-ask spreads (Welker 1995). Taken together, the evidence suggests that the market reaction to managers' earnings forecasts will be influenced by the managers' forecasting credibility. In the following sections, I outline theoretical arguments relating to why (and how) commitment to disclosure and prior forecast accuracy individually and jointly impact managers' forecasting credibility.

\section{COMMITMENT TO DISCLOSURE: MAIN EFFECTS}

Prior research on voluntary disclosures suggests that more-committed disclosers will be viewed favorably by markets relative to their less-committed peers. In prior studies, commitment to disclosure is typically inferred from increased disclosure (Leuz and Verrecchia 2000), or from increased frequency of disclosures (Botosan and Harris 2000, Brown et al. 2004).

In the context of management earnings forecasts, I define commitment to disclosure as a combination of frequent and predictable forecasting. Frequent forecasters are those who provide a greater quantity of forecasts during a given time period. For example, a firm that provides 12 forecasts over a three-year period is a more committed discloser, ceteris paribus, relative to a firm that provides three forecasts over the same time period. Predictable forecasters are those who provide forecasts periodically such that outsiders (e.g., analysts and investors) can reliably anticipate the issuance of such 
forecasts. ${ }^{9}$ For example, a firm that issues three forecasts over a three-year period and does so every year in December is a more committed discloser relative to a firm that issues three forecasts in a random fashion over that same time period. Thus, in my setting, more committed disclosers are those who provide earnings forecasts both frequently and predictably. Less committed disclosers, in contrast, provide earnings forecasts neither frequently nor predictably.

Defining the commitment to disclosure construct in terms of both frequency and predictability is important because it recognizes the multi-dimensional nature of the underlying construct. This approach to defining constructs (using more than one dimension) has been used previously in prior accounting research (e.g., Hackenbrack and Nelson 1996), and strengthens the power of the construct of interest. ${ }^{10}$ Defining commitment to disclosure solely in terms of either frequency or predictability would minimize the strength of the disclosure commitment construct in my study. I discuss my approach in greater detail in Appendix A and also in the experimental design section.

Managers appear to value being viewed as more committed disclosers (Graham et al. 2005), yet commitment to disclosure has received limited attention in previous studies. I first present some empirical evidence on how markets respond to more committed disclosers and then present theoretical arguments relating to how commitment to disclosure influences the two components of credibility - namely, trustworthiness and competence. Brown et al. (2004) find that firms that host conference calls regularly reduce their annual cost of capital by 15 basis points relative to firms that host such calls

\footnotetext{
${ }^{9}$ Note that predictability relates to the provision of the forecasts on a periodic basis and does not imply predictability about the content of the forecast.

${ }^{10}$ Specifically, Hackenbrack and Nelson (1996) use multiple dimensions to define engagement risk in an auditing setting.
} 
occasionally. ${ }^{11}$ More frequent management earnings forecasts are also associated with higher institutional ownership (Ajinkya et al. 2005). Managers generally prefer higher levels of institutional ownership because higher institutional ownership is generally associated with lower levels of stock mispricing (Jiambalvo et al. 2002). Firms that choose to provide earnings forecasts, but subsequently stop providing such forecasts experience a reduction in analyst coverage (Houston et al. 2006). Taken together, these findings suggest that market participants respond positively to more committed disclosers. These findings are consistent with the idea that more frequent disclosures reduce uncertainty in anticipated cash flows (Lambert et al. 2007) and reduce risk by minimizing stock price volatility (Diamond and Verrecchia 1991).

Although the number of firms providing earnings forecasts has increased over time, prior research suggests that, on average, managers appear to be less committed to providing earnings forecasts. ${ }^{12}$ That is, firms often provide forecasts in some periods, stay silent for several periods, and then resume their forecasts (Houston et al. 2006, Rogers and Stocken 2005). This behavior is puzzling for two reasons. First, a significant majority of managers express concern about being viewed as less committed disclosers. Managers rank concerns about commitment to disclosure ahead of proprietary cost and litigation cost concerns in influencing their voluntary disclosure decisions (Graham et al. 2005). Yet, their behavior appears to be at odds with this stated concern. Second, prior research on conference calls (Brown et al. 2004) and quarterly segment disclosures (Botosan and Harris 2000) suggests that voluntary disclosures, once initiated, tend to be sticky. Unlike these disclosures, management earnings forecasts do not appear to be

\footnotetext{
${ }^{11}$ Brown et al. (2004) define a firm as a regular caller in a particular calendar quarter if the firm had at least two calls in conjunction with its quarterly earnings announcements over the previous three calendar quarters. Firms that do not meet this criterion are categorized as occasional callers.

12 Firms issuing earnings forecasts now represent approximately 50 percent of Compustat on a valueweighted basis, up from 10-15 percent in the mid-1990's (Anilowski et al. 2007).
} 
sticky. That is, most firms continue to be ad hoc disclosers of forecasts (Houston et al. 2006, Rogers and Stocken 2005, Cotter et al. 2006).

I argue that managers who are more committed to disclosure are likely to be viewed as both more trustworthy and more competent relative to less committed peers. Underlying this argument is the expectation that investors react not just to disclosures, but also to non-disclosures (Nagar et al. 2003, Verrecchia 1983). First, investors are likely to place greater trust in managers who are more committed to providing disclosures predictably relative to their less committed peers. Supporting this idea, prior studies across a variety of domains show that predictability is an important determinant of trust. ${ }^{13}$ For example, predictability is an important determinant of trust in buyer-supplier relationships (Zaheer et al. 1998) as well as in superior-subordinate relationships (Cunningham and McGregor 2000). More predictable buyers and superiors are trusted more relative to less predictable buyers and superiors. Predictable behavior over time and across situations increases trust by reducing uncertainty about the trustee's actions (Whitener et al. 1998). In the earnings forecast context, investors who expect managers to provide regular earnings forecasts are more likely to trust the manager because of the reduced uncertainty about information availability.

Second, more committed forecasters are also likely to be viewed by investors as more able to anticipate and communicate changes in their firm's economic environment (Trueman 1986). In contrast, less committed forecasters may be viewed as less able to either anticipate or communicate changes in the firm's economic environment to investors. ${ }^{14}$ Thus, more committed forecasters are likely to be viewed as higher in

\footnotetext{
13 Predictability, per se, does not guarantee trust. Managers who always issue good-news earnings forecasts just before selling their shares are predictable, but they are also likely to be seen as self-serving. In such cases, the relationship between predictability and trust may be negative.

${ }^{14}$ Ad hoc forecasting may also be construed as managers' unwillingness (and not just inability) to communicate regularly with investors, which could negatively impact trustworthiness.
} 
forecasting competence relative to less predictable forecasters. In sum, both empirical evidence and theory suggest that more committed forecasters are likely to be viewed as both more trustworthy and more competent (and therefore, more credible) relative to less committed forecasters.

\section{PRIOR FORECAST ACCURACY: MAIN EFFECTS}

Investors appear to value and reward prior forecast accuracy. Current earnings forecasts from managers are generally viewed as more believable when managers have been more accurate in the past (Atiase et al. 2006, Hutton and Stocken 2007). Two illustrations from prior research underscore the value of prior forecast accuracy. First, the extent to which analysts update their earnings forecasts to be in line with a manager's earnings forecast is positively related to the manager's prior forecast accuracy (Williams 1996). Second, although the market generally under-reacts to good news management earnings forecasts, the extent of this under-reaction is lower for more accurate forecasters implying that investors assess the believability of a forecast conditional on prior forecast accuracy ( $\mathrm{Ng}$ et al. 2006).

Substantial variation exists in the accuracy of managers' earnings forecasts (Hassell and Jennings 1986, Chen 2004). For a sample of quarterly forecasts between 1994 and 2003, Chen (2004) finds that managers meet their forecasts 45 percent of the time, miss them 16 percent of the time and exceed them 39 percent of the time. Based on a sample of 1,039 annual forecasts during the period 2000-04, Hribar and Yang (2006) find that managers meet their annual forecasts six percent of the time whereas they miss them 46 percent of the time and exceed them 48 percent of the time.

I argue that accurate forecasts positively influence a manager's forecast credibility by influencing perceptions of the manager's trustworthiness as well as perceptions of forecasting competence. First, I expect that managers' prior forecast accuracy is 
positively related to investors' perceptions of managers' trustworthiness. Because high accuracy implicitly denotes lack of bias, managers who are highly accurate are likely to be seen as unbiased, and therefore, more trustworthy. ${ }^{15}$ Although low accuracy does not necessarily denote bias, if managers are inaccurate over a long period of time, investors' negative perceptions of managerial competence (for reasons outlined below) could spillover to trustworthiness judgments as well (Rozin and Royzman 2001). Therefore, in general, I expect managers who are more accurate to be viewed as more trustworthy relative to their less accurate peers.

Second, consistently accurate forecasts suggest that a manager is able to anticipate changes in the firm's business environment (Trueman 1986). On the contrary, if a manager consistently misses self-imposed earnings forecasts, the manager is likely to be perceived as less capable. Thus, more accurate managers are also likely to be viewed as more competent at forecasting relative to their less accurate peers. Consistent with this expectation, Hirst et al. (2003) find that investors judge more accurate forecasters to be more skilled and their financial reports to be of higher quality.

To summarize, I expect that both commitment to disclosure and prior forecast accuracy are positively related to investors' perceptions of managers' trustworthiness and forecasting competence — and thus, to managers' forecasting credibility. Managers' forecasting credibility, in turn, is positively related to how investors assess the credibility of a current disclosure from managers (disclosure credibility) and also to investors' valuation judgments (Mercer 2004). I do not, however, make any main effect predictions for commitment to disclosure or accuracy in light of the competing predictions about how

\footnotetext{
15 Prior research shows that high forecast accuracy is positively associated with perceptions of integrity (Tan et al. 2002), as well as with perceptions of forthcomingness (Mercer 2005) - both constructs closely related to trustworthiness.
} 
these two factors jointly influence manager's forecasting credibility. The competing arguments are outlined in greater detail in the following section.

\section{THE JOINT IMPACT OF COMMITMENT TO DISCLOSURE AND PRIOR FORECAST ACCURACY}

\section{Overview}

Drawing on the voluntary disclosure literature from economics (the normative perspective) and the omission bias literature from psychology (the omission bias perspective), I generate competing predictions about how investors jointly evaluate managers' commitment to disclosure and forecast accuracy to form inferences about managers' forecasting credibility. Although both perspectives suggest that commitment to disclosure and accuracy will jointly influence perceptions of managers' forecasting credibility, they make different predictions relating to whether the two factors interact. In the following sections, I first describe the normative perspective followed by the competing prediction based on the omission bias perspective.

\section{Normative Perspective}

Economic theory suggests that while assessing voluntary disclosures, investors evaluate both what managers say and what managers choose not to say (Dye 2001, Verrecchia 2001). Consistent with this literature, accounting studies of disclosure in single-period settings show that investors generally interpret managers' choice to withhold certain information (or to withhold the disclosure itself) as evidence that the undisclosed information is likely to be negative (Kennedy et al. 1998, Hobson and Kachelmeier 2005). That is, investors appear to recognize that silence represents a disclosure choice, and thus, react, both to disclosures and to non-disclosures in singleperiod settings. Over multiple periods, managers make choices with respect to voluntary disclosures. They disclose in some periods and choose to remain silent in others. Drawing 
on the economic literature on voluntary disclosure, I argue that investors make inferences about managers and react to managers' (current) disclosures based on these historical disclosure choices.

The voluntary disclosure literature posits that by voluntarily committing to increased disclosure, managers bind themselves, albeit weakly, to future disclosures. More important, managers maintain that once they commit to a voluntary disclosure, they set a precedent that binds them to future disclosures (Graham et al. 2005). For instance, managers who voluntarily list their firms on a stock exchange that requires increased levels of disclosure are deemed to be more committed to disclosure relative to their peers who choose not to do so (Leuz and Verrecchia 2000). In this study, I argue that managers who provide earnings forecasts both frequently and predictably commit themselves to a higher disclosure standard. Clearly, this commitment is tenuous in that it can be broken relatively easily. Managers can simply choose to stop providing earnings forecasts or they may provide forecasts only when they believe that the market earnings expectations need to be modified. Nonetheless, I argue that investors value commitment to disclosure, even when this commitment may be relatively less binding.

The belief that commitment to disclosure is valued by investors is reflected in investor reaction to more- versus less-committed disclosers outlined earlier. Recall that, ceteris paribus, managers who hold conference calls more frequently pay less for their capital relative to managers who hold such calls less frequently (Brown et al. 2004). Recall, also, that managers who display lower commitment to disclosure by discontinuing earnings guidance lose analyst coverage (Houston et al. 2006). Economic theory as well as models of voluntary disclosure suggests that managers who are less committed to disclosure will be viewed as less credible by investors (Stocken 2000). More important, 
prior research does not posit whether commitment to disclosure will interact with other aspects of the disclosure (such as prior accuracy of the disclosures).

Based on the discussion above, the normative perspective would predict that commitment to disclosure exerts an independent main effect that operates in concert with other attributes of managers' disclosures. That is, when commitment to disclosure is high, more accurate managers will be viewed as more credible relative to less accurate managers. When commitment to disclosure is low, again, more accurate managers will be viewed as more credible relative to less accurate managers, but the overall level of credibility will be lower because investors value commitment to disclosure. In other words, I argue that commitment to disclosure and prior forecast accuracy will jointly, but independently, influence managers' forecasting credibility. Figure 2 (panel A) provides a graphical representation of this prediction.

Economic theories of voluntary disclosure suggest that the primary mechanism by which commitment to disclosure and prior forecast accuracy jointly affect investor perceptions is through reduced information risk. That is, when managers are more committed to disclosure and the disclosures are reliable, the information risk associated with owning a stock decreases (Easley et al. 2002). The likelihood that investors may be forced to liquidate their investments during periods of sparse information when stock prices are volatile (Diamond and Verrecchia 1991) also decreases when managers are more committed to disclosure. In contrast, when managers are less committed to disclosure or less accurate (or both), the information risk associated with owning a stock increases. Investors will demand a premium to bear this increased information risk. Thus, risk is the primary mechanism that makes commitment to disclosure desirable from investors' standpoint. I test whether investors' perceptions of 
information risk are systematically related either to commitment to disclosure or to prior forecast accuracy, or to both.

\section{Omission Bias Perspective}

An alternative prediction about the interaction of commitment to disclosure and prior forecast accuracy is suggested by the omission bias literature. This literature posits that stronger inferences are made about a person based on action rather than inaction (Spranca et al. 1991, Baron and Ritov 1994). More committed disclosers are likely to be viewed as more active compared to less committed disclosers. ${ }^{16}$ Thus, the omission-bias literature would suggest that investors are likely to draw stronger (weaker) inferences about managers' trustworthiness and competence when managers are more-committed to disclosure than when they are less-committed to disclosure.

The omission bias literature predicts that outcomes that follow action (commissions) generally lead to much stronger reactions than outcomes that follow inaction (omissions). This finding has been documented both for both positive and for negative outcomes. ${ }^{17}$ For example, holding constant a negative outcome (number of deaths per 1000 people), participants judged deaths resulting from administering a vaccine to be a lower-quality decision compared to deaths resulting from non-vaccination (Baron and Ritov 1994). In other words, an act of commission leading to a negative outcome was judged more severely relative to an act of omission leading to an identical negative outcome.

\footnotetext{
16 Arguably, the distinction between action and inaction may not always be clear. Yet, participants in numerous studies (Baron and Ritov 1994, Landman 1987) appear to systematically distinguish between commissions and omissions. More important, in the context of the present study, the distinction is not between action and inaction per se, but between relative levels of action. I expect that more-committed forecasters will be seen as more active relative to less-committed forecasters. I test this expectation and find that it is supported in my setting.

17 The omission bias has largely been explored in the domain of negative outcomes. Baron and Ritov (1994) find only limited support for the omission bias in the domain of positive outcomes. However, see Landman (1987) for a replication of the omission bias for positive outcomes.
} 
To the extent that a company's high (low) forecast accuracy is viewed as a positive (negative) outcome, I expect that investors' assessment of managers' forecasting credibility will differ depending on whether the high or low accuracy is associated with more commitment to disclosure (high action) or less commitment to disclosure (low action). This expectation leads to the predictions outlined below.

When managers are more committed to disclosure, more accurate forecasters will be rated significantly higher in forecasting credibility compared to less accurate forecasters. In contrast, when managers are less committed to disclosure, the distinction in credibility assessments between more and less accurate forecasters will be less pronounced. Based on the omission bias literature, two corollaries follow this prediction. More committed disclosers will be viewed as significantly more credible relative to less committed disclosers when forecast accuracy is high. In contrast, more committed disclosers will be viewed as significantly less credible relative to less committed disclosers when forecast accuracy is low. Figure 2 (panel B) presents a graphical summary of these predictions.

Further research has posited two mechanisms by which the omission bias may operate. The first perspective suggests that acts of commission are more likely to be seen as decisions relative to acts of omission (Niedermayer and Chapman 2001, Kordes-de Vaal 1996) and therefore lead to stronger reactions. Because decisions are seen as more deliberate compared to non-decisions, stronger inferences will be drawn about a person based on their decisions. In other words, people will make stronger judgments about more committed disclosers because more committed disclosers are seen as making more deliberate decisions. In contrast, less committed disclosers are likely to be seen as passively accepting the default option of non disclosure. Thus, the decision versus nondecision dichotomy drives the omission bias. 
Some research suggests that in contexts where the default option or the norm is inaction, omissions will be viewed as consistent with the norm whereas commissions will be viewed as inconsistent with the norm (Prentice and Koehler 2003). Both positive and negative outcomes produced by norm-inconsistent behaviors attract much stronger reactions from people compared to identical outcomes resulting from norm-consistent behavior (Kahneman and Miller 1986). According to this perspective, it is not the decision versus non-decision dichotomy, but he norm-consistent versus norminconsistent dichotomy that drives the omission bias. A subsequent section outlines details of how I measure and test these alternative explanations.

\section{SUMMARY OF PREDICTIONS}

Figure 2 summarizes the competing predictions about the joint impact of commitment to disclosure and accuracy on judgments of managers' forecasting credibility. Although both perspectives - the normative perspective and the omission bias perspective suggest that commitment to disclosure and prior forecast accuracy will jointly influence managers' forecasting credibility, the perspectives differ in terms of how investors will combine the two factors in arriving at their judgments of managers' forecasting credibility. The normative perspective suggests that commitment to disclosure and prior forecast accuracy exert additive, but independent effects, on managers' forecasting credibility. In contrast, the omission bias literature suggests a commitment $\times$ accuracy interaction effect on managers' forecasting credibility. That is, more committed disclosers will be viewed as more credible, but only when prior forecast accuracy is high. When prior forecast accuracy is low, more commitment to disclosure hurts, rather than helps, managers' forecasting credibility.

As discussed previously, I also predict that investors' judgment of managers' forecasting credibility will be positively related to their judgments about the credibility of 
a current disclosure (disclosure credibility) and to their valuation judgments (Mercer 2004). Finally, I test alternative mechanisms by which commitment to disclosure and prior forecast accuracy potentially impacts managers' forecasting credibility based on the normative perspective (risk-based mechanism) and the omission bias perspective (the decision / norm based mechanism).

\section{EXPERIMENT}

\section{Design and Participants}

To test the competing predictions relating to the joint impact of commitment to disclosure and prior forecast accuracy on managers' forecasting credibility as well as my additional predictions, I conduct an experiment that employs a $2 \times 2$ full-factorial, between-participants design. Ninety three Masters of Business Administration (MBA) students participate in the experiment, which takes about 20 minutes to complete. Participants are paid a sum of $\$ 10$ for their participation. On average, participants have 4.94 years of work experience, and have taken 3.47 courses in finance and 3.13 courses in accounting. Although participants' work experience and the number of finance courses does not differ by experimental condition, the number of accounting courses taken differs across conditions $(\mathrm{F}=3.147, \mathrm{p}=.03)$. Results of an ANOVA confirm that the number of accounting courses, however, has neither a main effect nor does it interact with either of the primary independent variables (commitment to disclosure and accuracy) in explaining managers' forecasting credibility. Therefore, I do not expect the differential number of accounting courses taken by participants across conditions to materially impact the reported results.

The objective of this study is to examine how non-professional investors make judgments about managers' forecasting credibility based on information about managers' 
commitment to disclosure and prior forecast accuracy. I use MBA student-participants as a proxy for non-professional investors. Two factors drive this choice. The first reason I use MBA student-participants in the current study is because I wanted participants who have: (a) some investment experience and (b) some knowledge of the incentives faced by managers, both for disclosure and for non-disclosure. Given that the typical MBA student has at least a few years of work experience, I fully expect my participants to fulfill both criteria. Choosing less-sophisticated participants (say undergraduates) would require me to screen participants to ensure that they meet the two criteria before administering the study. Second, based on a framework advocated by Elliot et al. (2007), this study would be categorized as one that is relatively low in integrative complexity. Elliot et al. find that, for tasks that are relatively low in integrative complexity, MBA student-participants' judgments are an appropriate proxy for judgments by non-professional investors.

It is important to recognize that are about half of all equity investors, or 28.4 million households (non-professional investors) invest directly in the stock market (Securities Industry Association 2005). Non-professional investors, therefore, represent an important investment population whose investment judgments and decisions should be of interest to regulators. Although the size of the potential population of non-professional investors is a good reason to examine their investment judgments and decisions, any claims about the generalizability of this study's results to such a large population must be tempered with caution.

In this paper, I examine quarterly management earnings forecasts for two reasons. First, in a survey of 654 of its members, the National Investor Relations Institute (NIRI 2006) reported that more than half of the firms surveyed provide quarterly earnings forecasts. Quarterly earnings forecasts provide a stronger setting to examine commitment to disclosure - one of the two independent variables in this study. Managers who 
provide only annual earnings forecasts are unlikely to be viewed as committed to disclosure, particularly when a majority of firms provide quarterly earnings forecasts. Second, prior research in other disclosure contexts (for example, segment reporting) documents strong investor demand for quarterly reporting (Botosan and Harris 2000)..$^{18}$ Consistent with stronger investor demand, prior research shows that quarterly earnings forecasts are more informative in that they lead to stronger stock price reactions relative to annual earnings forecasts (Pownall et al. 1993).

\section{Materials, Manipulations, and Questions}

The experiment is administered in three parts. Figure 3 provides an overview of the information provided and the questions asked in each of the three parts. The first part of the experiment contains background information and three prior years' summarized financial data for Zeta - a hypothetical company in the electrical equipment industry. Participants are informed that Zeta has provided management earnings forecasts voluntarily in some prior periods. At this stage, no information is provided to participants either about Zeta's commitment to disclosure or about the accuracy of these forecasts.

To minimize the possibility that participants might make inferences that historical forecasts may be biased, participants are told that Zeta's earnings forecasts (compared to reported earnings) were not systematically biased in one direction. Participants are also told that Zeta's prior forecasts include a mix of good and bad news. This information is provided to address the concern that participants may assume that managers systematically provide earnings forecasts only when there is a particular type of news. For instance, if participants assume that managers provide forecasts only when there is bad news, they may not view fewer forecasts as a sign of lack of commitment to

\footnotetext{
18 Underscoring investor demand for more frequent reporting, Botosan and Harris (2000) report, based n a FASB study that "users contended that, to be timely, segment information is needed more often than annually..." (p. 330)
} 
disclosure. They may, instead, view fewer disclosures as reflecting a systematic policy of communicating only a particular type of news. This assumption, if made, is a concern because it weakens the commitment to disclosure manipulation. Framing the newscontent of prior forecasts as a mix of good and bad news should mitigate this concern.

Based on this information, participants assigned to the role of potential investors provide their initial assessment of managers' forecasting credibility - the primary dependent variable in the study. Participants also provide their assessment of managers' trustworthiness and forecasting competence and provide a price - earnings (P/E) multiple for Zeta. Participants are told that other firms in Zeta's industry trade at multiples of trailing earnings between 15 and 25 times. Because all participants view the same information, systematic differences in their initial judgments are not expected.

Following part one, the manipulations are then introduced. Participants are assigned to one of four conditions. The four conditions are obtained by crossing two levels of managers' commitment to disclosure (more versus less committed) and two levels of managers' prior forecast accuracy (high versus low). The only new information provided in part two is information about Zeta's commitment to disclosure and prior forecast accuracy. Given that the objective of the experiment is to measure how participants react to information about commitment to disclosure and prior forecast accuracy (and not whether or not they attend to this information), I use a two-stage design that increases the likelihood that participants will notice the manipulations (Libby et al. 2002). I use the scores obtained in the first part of the experiment as covariates in subsequent analyses.

Participants assigned to the condition in which managers are more (less) committed to disclosure are informed that managers provide voluntary earnings forecasts 
in twelve (four) of the preceding twelve quarters. ${ }^{19}$ Importantly, participants are told that the twelve forecasts are provided one in each quarter (i.e. predictably in each quarter for the past three years). In contrast, participants in the less committed condition are told that the four forecasts were provided in different quarters in each of the three years (i.e. apparently at random and therefore unpredictably).

Consistent with my definition of commitment to disclosure, my manipulation is designed to capture the idea that more committed managers provide disclosures both frequently and predictably (cf. Hackenbrack and Nelson 1996). ${ }^{20}$ In contrast, less committed managers are neither frequent nor predictable. I manipulate the two extremes (high frequency and high predictability compared to low frequency and low predictability) to maximize the likelihood that I should detect an effect for the treatment, should one exist. I do not examine cases where managers provide (a) highly frequent, but unpredictable forecasts or (b) highly predictable, but infrequent forecasts. Managers who issue highly frequent, but unpredictable earnings forecasts are unlikely to be seen as more committed to disclosure. That is, they sacrifice an important ingredient that makes disclosures more relevant — predictability. Similarly, managers who are highly predictable, but infrequent disclosers, are also unlikely to be viewed as more committed to disclosure. That is, they sacrifice an important ingredient that makes disclosures more

\footnotetext{
19 The basis for the choice of twelve versus four quarterly forecasts in a three year period is the following: for a sample of quarterly management earnings forecasts during the period 2001 to 2003 (12 quarters), Cheng et al. (2005) find that dedicated forecasters (the top one-third of their sample) provide forecasts in 10 out of 12 quarters, whereas occasional forecasters (comprising the bottom one-third of their sample) provide forecasts in only one out of the 12 quarters. The levels chosen in the experiment are, therefore, (a) adequately separate to detect a treatment effect, should one exist, and (b) correspond to real-world conditions (Libby et al. 2002). Although I could choose less than four quarters to operationalize the less committed to disclosure condition, I choose four quarters to ensure that my predictions can be meaningfully tested. For instance, if I chose just one quarter (out of twelve) to operationalize low commitment to disclosure, the main effect for commitment to disclosure could overwhelm any other effects.

${ }^{20}$ Specifically, Hackenbrack and Nelson (1996) manipulate auditor engagement risk in an audit setting using multiple dimensions of risk. The three specific dimensions they use are: (1) pressure from lenders, (2) impending initial public offering and (3) age of audit client. They simultaneously manipulate all three of these variables to create a more powerful manipulation of engagement risk.
} 
relevant - frequency. Therefore, my operationalization of commitment to disclosure varies both frequency and predictability.

Turning next to the accuracy manipulation, participants in the high (low) forecast accuracy condition are informed that Zeta is ranked in the top (bottom) 10 percent of its peers in terms of forecasting accuracy over the past three years. There are two advantages to providing a relative rank for accuracy. First, if I were to require participants to compute accuracy, this procedure has the potential to divert their attention away from the question of interest. In contrast, providing accuracy rankings minimizes this possibility. Second, ranking managers' forecast accuracy relative to peers rather than providing an absolute measure of accuracy (say, managers were accurate in 8 of 12 quarters) ensures that participants do not have to make assumptions about general levels of accuracy for management forecasts. Following this information, participants respond to the same questions asked at the end of part one of the experiment. That is, participants provide their revised assessment of managers' forecasting credibility, manager's trustworthiness, forecasting competence, and a P/E ratio for Zeta.

Part three of the experiment has two objectives. First, it seeks to verify whether participants' perceptions of managers' forecasting credibility (obtained in the previous parts of the experiment) is related to how they view a current earnings forecast from Zeta. In other words, it tests the claim that managers' forecasting credibility is positively related to disclosure credibility — the credibility of a specific disclosure (Mercer 2004). Second, participants are asked several questions to see how they reasoned through the experimental material to better understand the process by which the treatments influence participant judgments. Recall that the normative perspective and the omission bias perspective suggest two alternative mechanisms by which commitment to disclosure and prior forecast accuracy might influence managers' forecasting credibility. Part three 
provides a current earnings forecast from Zeta. This forecast states that Zeta expects earnings per share (EPS) will be $\$ 0.31$ for the upcoming quarter. Participants are also told that this estimate is four cents above the latest consensus analyst EPS forecast of $\$$ 0.27 .

Following the current earnings forecast provided in part three, I ask participants several questions to accomplish the two objectives listed above. The first set of questions seeks participants' responses to the current earnings forecast. Participants provide their assessment of the credibility of the current earnings forecast and answer several additional questions relating to the current forecast. The second set of questions seeks to capture the underlying mechanisms that drive the relationship between commitment to disclosure, prior forecast accuracy, and managers' forecasting credibility. Specifically, I ask participants about their perceptions of information risk, the extent to which Zeta's forecasts represent decision making by Zeta's managers, and whether Zeta's forecasting behavior is consistent with norms. In addition to these questions, I ask questions to check that participants understand the manipulations as intended. A final set of questions obtains demographic information to verify whether participant responses vary systematically based on any specific demographic variable. The complete experimental materials are reproduced in Appendices B through G.

\section{RESULTS}

\section{Manipulation and Other Checks}

I first present participant responses to questions that check the primary manipulations - managers' commitment to disclosure and prior forecast accuracy. I also discuss participants' responses to several other questions to check that participants interpret the experimental materials as intended. To check that participants view the 
commitment to disclosure manipulation as intended, I ask participants to rate their beliefs about Zeta's managers' commitment to disclosure relative to their peers on a scale where 0 indicates below average and 10 indicates above average. As expected, participants assigned to the condition where managers are more committed to disclosure rate managers' commitment to disclosure significantly higher than participants assigned to the condition where managers are less committed to disclosure $\left(\bar{X}_{\text {more committed }}=6.87, \bar{X}_{\text {less }}\right.$ committed $=4.75, \mathrm{t}=5.89, \mathrm{p}<.01) .{ }^{21}$

For the forecaster accuracy manipulation, participants check one of three response options. The options are whether Zeta's earnings forecast accuracy is: (a) in the top 10\% of its industry (b) in the bottom $10 \%$ of its industry and (c) cannot recall. Ninety eight percent (93\%) of the participants in the high- (low-) accuracy condition respond correctly to this question. Responses are significantly associated with the experimental condition $\left(\chi_{1}^{2}=30.57, \mathrm{p}<.01\right)$ indicating that the accuracy manipulation is effective. ${ }^{22}$

To invoke the omission bias, it is important to verify that participants believe that more committed disclosers are more active whereas less committed disclosers are (relatively) less active. Participants respond to a question that asks whether Zeta's forecasting history reflects low or high levels of forecasting activity on part of Zeta's managers. Scale endpoints are 0 denoting low levels of forecasting activity and 10 denoting high levels of forecasting activity. As expected, participants rate more committed disclosers as more active relative to less committed disclosers $\left(\bar{X}_{\text {more committed }}\right.$ $\left.=5.7, \bar{X}_{\text {less committed }}=4.1, \mathrm{t}=3.22, \mathrm{p}=.002\right)$.

\footnotetext{
${ }^{21}$ Note that all questions relating to the manipulations are asked towards the end of the experiment to minimize the possibility of hypothesis-guessing. For the exact location of the questions, please see Appendices B through G.

22 One participant did not answer any of the manipulation check questions. Excluding responses from this participant or from participants who failed one or more of the manipulation checks does not alter any of the inferences.
} 
Participants respond to additional questions aimed at checking for assumptions that could impact the observed results. Two specific concerns are: (a) participants may confound accuracy and bias, and (b) participants may assume that managers systematically provide earnings forecasts only when they have a specific type of news (e.g., bad news). If participants across conditions make systematically different assumptions about managers' bias, these assumptions could impact participants' credibility judgments via their judgments of managers' trustworthiness. Also, if participants assigned to the condition in which managers are less committed to disclosure assumed that managers always communicated a specific type of news, they may not view infrequent disclosers as less committed to disclosure, thereby weakening the commitment to disclosure manipulation.

Participants check one of four response options with respect to their perceptions of Zeta's forecast bias. The options are whether Zeta's forecast errors are mostly: (a) positive - forecasts are mostly lower than reported earnings, (b) negative - forecasts are mostly higher than reported earnings, (c) neutral, or (d) cannot recall. Ninety three percent of the participants across conditions respond that forecast errors are neutral. Responses are not significantly associated with experimental condition $\left(\chi_{1}^{2}=0.13, \mathrm{p}=\right.$ .72) indicating that the participants across conditions appeared to believe that, on average, Zeta's forecast errors were neutral, and therefore, did not connote systematic bias.

Similarly, participants check one of four response options with respect to their perceptions of the news content of Zeta's earnings forecasts. The options are whether Zeta's earnings forecasts mostly conveyed: (a) good news, (b) bad news, (c) a mix of good and bad news, or (d) cannot recall. Ninety three percent of the participants across conditions indicate that Zeta's forecasts represent a mix of good and bad news. 
Responses are not significantly associated with experimental condition $\left(\chi_{1}^{2}=0.18, \mathrm{p}=\right.$ .67) indicating that the participants across conditions held equivalent perceptions of the news content of Zeta's earnings forecasts.

Finally, participants respond to a question that aims to check whether they hold equivalent perceptions about how difficult (or easy) it is for Zeta's managers to forecast earnings across experimental conditions. To the extent that participants hold systematically different perceptions about the ease of forecasting earnings across experimental conditions, it is possible that these perceptions may systematically influence participants' judgments of managers' forecasting credibility. Participants rate their perceptions of the ease of forecasting Zeta's earnings on a 10 point scale with 0 denoting "very easy" to forecast and 10 representing "very difficult" to forecast. Not surprisingly, participants in the high-accuracy conditions report that it is (relatively) easier to forecast Zeta's earnings compared to participants in the low-accuracy conditions $(\mathrm{t}=3.32, \mathrm{p}<$ .01). However, ease of forecasting has neither a main effect nor does it interact with the primary independent variables (commitment to disclosure and accuracy) in explaining managers' forecasting credibility. Therefore, differential perceptions of ease (or difficulty) of forecasting per se should not materially impact the reported results.

\section{Tests of Hypotheses}

I have two competing predictions about the joint impact of managers' commitment to disclosure and prior forecast accuracy on managers' forecasting credibility. The normative perspective suggests that commitment to disclosure and prior forecast accuracy exert an additive impact on managers' forecasting credibility (i.e., two main effects). In contrast, the omission bias perspective suggests a commitment $\times$ accuracy interaction on managers' forecasting credibility. Figure 2 summarizes the competing predictions. Because I define managers' forecasting credibility in terms of 
managers' trustworthiness and managers' forecasting competence, I present the results for trustworthiness and competence first before presenting the results for participants' perceptions of managers' forecasting credibility.

Based on Zeta's management earnings forecasts and other background information, I first ask participants about the credibility of Zeta's managers' forecasts. Scale endpoints are 0 (not at all credible) and 10 (highly credible). Second, participants provide their assessment of the trustworthiness of Zeta's managers. Scale endpoints are 0 (not at all trustworthy) and 10 (highly trustworthy). Third, participants provide their assessment of the forecasting competence of Zeta's managers. Scale endpoints are 0 (not at all competent) and 10 (highly competent). Results of a MANOVA (not tabulated) on all three dependent variables - managers' trustworthiness, managers' forecasting competence, and managers' forecasting credibility, shows a significant commitment $\times$ accuracy interaction (Wilks Lambda $\mathrm{F}=7.80, \mathrm{p}<.01$ ), a non-significant main effect for commitment to disclosure (Wilks Lambda $\mathrm{F}=.39, \mathrm{p}=.76$ ), and a significant main effect for prior forecasting accuracy (Wilks Lambda $\mathrm{F}=95.98, \mathrm{p}<.01$ ). I present the results of the related ANOVA's for trustworthiness and competence first before presenting the results for managers' forecasting credibility.

\section{Judgments of Managers' Trustworthiness}

Panel A of Table 1 presents participants' assessment of managers' trustworthiness before and after the manipulations of managers' commitment to disclosure and accuracy. Participants' initial judgments of managers' trustworthiness do not vary across conditions $(\mathrm{F}=1.34, \mathrm{p}=0.27)$ as expected. Panel B of Table 1 presents the results of an ANCOVA model with participants' initial judgment of managers' trustworthiness as a covariate, commitment to disclosure and accuracy as independent variables and participants' final perceptions of managers' trustworthiness as the dependent variable. The ANCOVA 
reveals a significant main effect for the covariate $(\mathrm{F}=12.64, \mathrm{p}<.001)$, an insignificant main effect for commitment to disclosure $(F=0.97, p=.327)$, a strongly significant main effect for accuracy $(\mathrm{F}=49.26, \mathrm{p}<.001)$, and a strong interaction effect for the commitment $\times$ accuracy interaction $(\mathrm{F}=15.44, \mathrm{p}<.001)$.

Panel C presents the simple main effects of commitment to disclosure on participants' perceptions of trustworthiness at low and high levels of accuracy. Panel D presents the simple main effects of prior forecast accuracy on perceptions of trustworthiness for the more- and less-committed conditions. Consistent with the omission bias explanation, both pairs of simple main effects are significant. Commitment to disclosure is significantly associated with perceptions of trustworthiness both at low levels of accuracy $(\mathrm{F}=4.13, \mathrm{p}=.023)$ and at high levels of accuracy $(\mathrm{F}=12.13, \mathrm{p}<$ .001). Similarly, accuracy is significantly associated with trustworthiness, both when managers are less committed to disclosure $(\mathrm{F}=4.75, \mathrm{p}=.016)$ and when they are more committed to disclosure $(\mathrm{F}=60.72, \mathrm{p}<.001)$.

Overall, managers' commitment to disclosure significantly impacts investors' perceptions of managers' trustworthiness, both when forecast accuracy is high and when it is low, albeit in different directions. The results are thus consistent with the predictions based on the omission bias perspective and inconsistent with the predictions based on the normative perspective. For a graphical representation of these results, see Figure 4 (panel A).

\section{Judgments of Managers' Forecasting Competence}

Panel A of Table 2 presents participants' judgment of managers' forecasting competence before and after the manipulations. Participants' initial judgments of managers' forecasting competence do not vary across conditions $(\mathrm{F}=0.46, \mathrm{p}=0.71)$ as expected. Panel B of Table 2 presents the results of an ANCOVA model with 
participants' initial judgment of managers' forecasting competence as a covariate, commitment to disclosure and accuracy as independent variables and participants' final perceptions of managers' competence as the dependent variable. The ANCOVA reveals a significant main effect for the covariate $(\mathrm{F}=19.78, \mathrm{p}<.001)$, an insignificant main effect for commitment to disclosure $(\mathrm{F}=1.01, \mathrm{p}=.317)$, a strongly significant main effect for accuracy $(\mathrm{F}=245.01, \mathrm{p}<.001)$, and a strong interaction effect for the commitment $\times$ accuracy interaction $(\mathrm{F}=15.44, \mathrm{p}<.001)$.

Panel $\mathrm{C}$ presents the simple main effects of commitment to disclosure on participants' perceptions of forecasting competence at low and high levels of accuracy. Panel D presents the simple main effects of prior forecast accuracy on perceptions of forecasting competence for the more- and less-committed conditions. Consistent with the omission bias explanation, both pairs of simple main effects are significant. Commitment to disclosure is significantly associated with perceptions of competence both at low levels of accuracy $(F=4.16, p=.022)$ and at high levels of accuracy $(F=12.33, p<.001)$. Similarly, accuracy is significantly associated with perceptions of competence, both when managers are less committed to disclosure $(F=67.86, p<.001)$ and when they are more committed to disclosure $(\mathrm{F}=193.80, \mathrm{p}<.001)$.

Again, the results are consistent with the omission bias prediction. That is, managers' commitment to disclosure positively and significantly impacts investors' perceptions of managers' forecasting competence when forecast accuracy is high. These results are reversed when forecast accuracy is low. For a graphical representation of these results, see Figure 4 (panel B). 


\section{Judgments of Managers' Forecasting Credibility}

Participants' judgments of managers' forecasting credibility are largely similar to their trustworthiness and competence judgments. ${ }^{23}$ Participants' initial judgments of managers' forecasting credibility do not vary across conditions $(\mathrm{F}=0.13, \mathrm{p}=0.94)$ as expected. Panel A of Table 3 presents participants' assessment of managers' forecasting credibility before and after the manipulations of managers' commitment to disclosure and accuracy. Panel B of Table 3 presents the results of an ANCOVA model with participants' initial assessment of managers' forecasting credibility as a covariate, forecasters' commitment to disclosure and prior forecast accuracy as independent variables and participants' final (post-manipulation) perceptions of managers' forecasting credibility as the dependent variable. The ANCOVA reveals a significant effect for the covariate $(\mathrm{F}=7.11, \mathrm{p}=.009)$, an insignificant main effect for commitment to disclosure $(\mathrm{F}=0.38, \mathrm{p}=.54)$, a strongly significant main effect for accuracy $(\mathrm{F}=139.68, \mathrm{p}<.001)$, and a strong interaction effect for the commitment $\times$ accuracy interaction $(F=9.94, p=$ $.002) .24$

Panel C presents the simple main effects of commitment to disclosure on participants' perceptions of managers' forecasting credibility at low and high levels of accuracy. Panel D presents the simple main effects of prior forecast accuracy on

\footnotetext{
${ }^{23}$ Consistent with prior literature, I assume that participants equally weight perceptions of competence and trustworthiness while arriving at their judgments of managers' forecasting credibility (Barton and Mercer 2005, Mercer 2005). To check the validity of this assumption, I regress participants' final credibility judgments (MFC) on participants' final competence (COMP) and trustworthiness (TRUST) judgments. MFC $=\alpha+\beta_{1} *$ COMP $+\beta_{2} *$ TRUST $+\varepsilon i$

Coefficients for COMP $\left(\beta_{1=0.42)}\right)$ and TRUST $\left(\beta_{2}=0.59\right)$ are both significant, suggesting that participants use both competence and trustworthiness judgments to arrive at credibility judgments. More importantly, the coefficient weights, however, are not statistically different (i.e., $\beta_{1}=\beta_{2}, p>.05$ ), suggesting that perceptions of trustworthiness and competence are approximately equally weighted in arriving at a composite credibility judgment.

${ }^{24}$ Using the difference scores between the final and initial judgments of trustworthiness, competence, and managers' forecasting credibility as dependent variables yields results that are similar to the results reported above.
} 
perceptions of forecasting credibility for the more- and less-committed conditions. Consistent with the omission bias explanation, both pairs of simple main effects are significant. Commitment to disclosure is significantly associated with perceptions of credibility both at low levels of accuracy $(\mathrm{F}=3.18, \mathrm{p}=.039)$ and at high levels of accuracy $(\mathrm{F}=7.15, \mathrm{p}<.001)$. Similarly, accuracy is significantly associated with perceptions of credibility, both when managers are less committed to disclosure $(\mathrm{F}=$ $37.18, \mathrm{p}<.001)$ and when they are more committed to disclosure $(\mathrm{F}=113.26, \mathrm{p}<.001)$.

Overall, the results for participants' perceptions of managers' forecasting credibility are again consistent with the omission bias perspective and inconsistent with the normative perspective. ${ }^{25}$ Commitment to disclosure exerts a significant positive influence on participants' assessments of managers' forecasting credibility for highly accurate managers. In contrast, commitment to disclosure exerts a significant negative influence on participants' assessments of managers' forecasting credibility for managers whose prior forecast accuracy is low. For a graphical representation of these results, see Figure 4 (panel C).

\section{Other Judgments}

Participants' judgment of managers' forecasting credibility based on historical forecasting behavior is important to the extent that it influences (a) their assessment of the credibility of a current disclosure and (b) their valuation judgments. Participants answer additional questions that shed some light on these questions. First, to test whether

\footnotetext{
25 Participants assigned to the conditions where managers are less committed to disclosure might respond around the midpoint of the scale on the three key variables because they did not have sufficient data to reach stronger conclusions (see, for example the flat-line results for participants' perceptions of trustworthiness in the less-committed conditions). If, indeed, participants' responses clustered around the midpoint - it is plausible that the reported results reflect insufficient data rather than strongly held beliefs. Analysis of participants' responses on all three variables suggests that fewer than $20 \%$ of participants responded in or around the midpoint of the scale (i.e., between 4.5 and 5.5), allaying any concerns that the results are driven by participants' ambivalence.
} 
participants' judgments of the credibility of a current disclosure is positively associated with their judgments of managers' forecasting credibility, they are presented with an earnings forecast disclosure for an upcoming quarter for Zeta and asked to provide their assessment of the credibility of that specific earnings forecast. Response scale endpoints are 0 (not at all credible) and 10 (highly credible). Consistent with expectations, participants' assessment of disclosure credibility (i.e., the believability of a specific earnings forecast) is positively and significantly correlated with participants' (final) judgments of managers' forecasting credibility $(\mathrm{r}=0.67, \mathrm{p}<.001)$. More important, an ANOVA with disclosure credibility as the dependent variable, commitment to disclosure and accuracy as independent variables reveals an insignificant main effect for commitment to disclosure $(\mathrm{F}=2.18, \mathrm{p}=.143)$, a significant main effect for accuracy $(\mathrm{F}=$ $80.20, \mathrm{p}<.001)$, and a significant interaction effect for the commitment $\times$ accuracy interaction $(\mathrm{F}=6.50, \mathrm{p}=.0125)$ reinforcing the idea that managers' forecasting credibility influences how investors are likely to view additional disclosures from managers. Table 4 presents descriptive statistics (panel A) and the results of this ANOVA (panel B).

Second, to answer the question whether participants' valuation judgments are affected by the experimental treatments, participants are asked to provide a price to earnings ratio $(\mathrm{P} / \mathrm{E})$ for Zeta, both before and after the manipulations. Participants are informed that other firms in Zeta's industry trade at multiples of trailing earnings of between 15 and 25 times. A few participants provided P/E ratios that were unusable. Participants who provided P/E ratios that were greater than 35 or lower than 5 were excluded from the analysis. This rule resulted in the exclusion of $\mathrm{P} / \mathrm{E}$ ratios provided by 5 
participants. Therefore, the data reported below relate to 88 participants (93 participants less 5 unusable responses). ${ }^{26}$

Panel A of Table 5 presents participants' P/E judgments before and after the manipulations. As expected, participants' initial $\mathrm{P} / \mathrm{E}$ judgments do not vary across conditions $(\mathrm{F}=0.83, \mathrm{p}=0.483)$. Participants' final $\mathrm{P} / \mathrm{E}$ judgments, however, do vary across conditions, consistent with participant judgments for the other dependent measures. Panel B of Table 5 presents an ANCOVA with participants' initial P/E judgment as a covariate, commitment to disclosure and accuracy as independent variables, and participants' final P/E judgments as the dependent variable. The ANCOVA shows a significant effect for the covariate $(\mathrm{F}=71.04, \mathrm{p}<.001)$, an insignificant main effect for commitment to disclosure $(\mathrm{F}=2.57, \mathrm{p}=0.113)$, a significant main effect for accuracy $(\mathrm{F}=54.51, \mathrm{p}<.001)$, and a significant interaction effect for the commitment $\times$ accuracy interaction $(\mathrm{F}=8.36, \mathrm{p}=.005)$. In other words, the multiple that participants are willing to pay for Zeta's earnings varies systematically, following the pattern for the other dependent variables. Therefore, participants' valuation judgments appear to correspond with their judgment of managers' forecasting credibility.

Panel C presents the simple main effects of commitment to disclosure on participants' P/E judgments at low and high levels of accuracy. Participants appear to distinguish between more- and less-committed managers with respect to P/E only when managers are highly accurate $(\mathrm{F}=10.00, \mathrm{p}=.001)$. When managers are less accurate, participants' $\mathrm{P} / \mathrm{E}$ judgments do not differ significantly based on commitment to disclosure $(\mathrm{F}=0.83, \mathrm{p}=.18)$. In other words, the omission bias prediction is not fully supported. Panel D presents the simple main effects of prior forecast accuracy on participants' P/E judgments for the more- and less-committed conditions. Accuracy is

${ }^{26}$ Re-running the analyses for the main dependent variables - perceptions of trustworthiness, competence, and credibility - excluding responses from these 5 participants does not alter the results. 
significantly associated with participants' P/E judgments, both when managers are more committed to disclosure $(\mathrm{F}=52.74, \mathrm{p}<.001)$ and when they are less committed to disclosure $(\mathrm{F}=9.95, \mathrm{p}=.001)$. It is important to note that the lack of support for the omission bias perspective does not automatically imply that the normative perspective is supported. If the normative perspective was supported, we should not expect to see the commitment $\times$ accuracy interaction. The results for participants' $\mathrm{P} / \mathrm{E}$ judgments, however, are less strongly supportive of the omission bias perspective compared to the results for the other dependent variables.

\section{Additional Analyses: Structural Equation Model}

To better understand how commitment to disclosure and prior forecast accuracy jointly influence managers' forecasting credibility, I also test the mechanisms suggested by the normative and the omission bias perspectives. Recall that the normative perspective suggests a risk-based mechanism whereas the omission bias perspective suggests a decision or a norm-based mechanism. I test the risk-based mechanism first before turning to the mechanisms proposed by the omission bias perspective.

To measure participants' perceptions of risk related to Zeta's stock, I ask three questions. The first question asks participants whether they believe Zeta's stock is more or less risky relative to its peers. Participants respond on a scale with endpoints of 0 denoting less risky and 10 denoting more risky. The second question asks whether Zeta's stock price is likely to be volatile. Participants respond on a scale with endpoints of 0 denoting highly volatile and 10 denoting not at all volatile. A third question asks how much effort participants expect to spend monitoring their investment in Zeta (assuming they choose to invest). Participants respond on a scale with endpoints of 0 denoting a lot 
of effort and 10 denoting very little effort. ${ }^{27}$ This question aims to capture the information risk associated with owning Zeta's stock. Based on a Cronbach's alpha score of 0.70 , it appears that all three questions appear to be measuring a common underlying construct (Peterson 1994). Additionally, the results of a factor analysis conducted on participants' responses to these three questions suggests a single underlying factor as well, with the factor loadings on individual questions well above 0.40 - a generally accepted cutoff for a meaningful factor loading (Hatcher 1994). I therefore use a composite score averaging participants' responses on these three questions as a proxy for participants' risk perceptions about Zeta.

As expected, participants' composite risk scores are systematically associated with the prior forecast accuracy treatment. That is, participants assigned to the high accuracy condition rate risk to be systematically lower compared to participants assigned to the low accuracy condition $(\mathrm{t}=5.61, \mathrm{p}<.01)$. Contrary to the prediction of the normative perspective, however, participants' composite risk scores are not systematically associated with the commitment to disclosure treatment. That is, participants assigned to condition in which managers are more committed to disclosure do not rate risk to be different compared to participants assigned to the condition in which managers are less committed to disclosure $(\mathrm{t}=.72, \mathrm{p}=.47) .{ }^{28}$ Not surprisingly, results of a structural equation model (not tabulated) confirm that the path between commitment to disclosure and the risk-based measure is not significant regardless of accuracy (High accuracy $\mathrm{t}=-.63, \mathrm{p}=.14$; Low accuracy $\mathrm{t}=.04, \mathrm{p}=.92$ ). In addition, the overall fit of a model incorporating the risk-based measure as a mediator reveals a poorly-fitting model $\left(\chi_{13}^{2}=24.62, p=.03\right)$. One potential explanation for this result is the

\footnotetext{
${ }^{27}$ Responses to the second and third question relating to risk are reverse-scored to ensure that endpoints consistently capture low and high risk.

${ }^{28}$ Using participants' scores on individual questions, instead of the composite score, leads to the same results.
} 
possibility that the case materials do not provide adequate information for participants to make a meaningful assessment of risk. Subject to this caveat, it does not appear that participants are making differential assessment of information risk based on commitment to disclosure.

The omission bias literature posits that people will make stronger judgments about more committed disclosers because more committed disclosers are likely to be seen as making more deliberate decisions. In contrast, less committed disclosers are likely to be seen as passively accepting the default option of non disclosure and thus likely to be seen as making less deliberate decisions. Thus, according to this perspective, the decision versus non-decision dichotomy drives the interaction between commitment to disclosure and prior forecast accuracy predicted by the omission bias. To test the validity of this claim, I obtain participants' perceptions of whether more committed disclosers are indeed seen as engaging in more deliberate decision making relative to less committed disclosers. Participants respond to a question that asks them to rate whether Zeta's managers choose to provide earnings forecasts every quarter after careful deliberation. Scale endpoints are 0 denoting very little deliberation and 10 denoting a great deal of deliberation. Contrary to expectations, participants assigned to the condition where managers are more committed to disclosure rate managers as less deliberate relative to participants assigned to the condition where managers are less committed to disclosure ( $\mathrm{t}$ $=3.75, \mathrm{p}<.01$ ). In other words, more commitment to disclosure (or action, in omission bias terms) appears to be associated with less, rather than more deliberate decisionmaking. A structural equations model with participants' perceptions of (deliberate) decision-making mediating the relationship between commitment to disclosure, prior forecast accuracy, and managers' forecasting credibility fits the data well $\left(\chi_{13}^{2}=11.74, p\right.$ $=.55)$, but the results are in the opposite direction from that predicted by the omission 
bias literature. Thus, it appears unlikely that the decision versus non-decision distinction drives the interaction results reported in the previous sections.

As noted earlier, another explanation for the observed pattern of results is suggested by Prentice and Koehler (2003). They argue that people demarcate observed behavior not along the lines of decision versus non-decision (as generally suggested by omission bias), but along the lines of whether the behavior is norm-consistent versus norm-inconsistent. Further, they argue that people react more strongly to outcomes that arise from norm-inconsistent rather than norm-consistent behaviors.

In the context of this study, more committed disclosers should be viewed as norminconsistent because management earnings forecasts are voluntary disclosures. That is, more committed disclosers are likely to be viewed as exceeding disclosure norms. In contrast, less committed disclosers to disclosure should, on average, be viewed as normconsistent. Therefore, commitment to disclosure should be negatively related to perceptions of norm-consistency. The relationship between perceptions of normconsistency and managers' forecast credibility, in turn, should be moderated by prior forecast accuracy.

To test this norm-based explanation, I conduct a structural-equations analysis that simultaneously estimates the relationships between my manipulated variables (commitment to disclosure and prior forecast accuracy), a mediating variable (participants' perceptions of norm-consistency), and my dependent variable — managers' forecasting credibility. Figure 5 presents the results of this analysis. I first confirm the model's goodness of fit with a conventional $\chi^{2}$ test $\left(\chi_{13}^{2}=17.96, p=.16\right)$ and an incremental fit index (IFI) of $0.90 .{ }^{29}$ To obtain a measure that estimates the proposed mediating variable, I ask participants to rate whether Zeta's earnings forecast frequency

${ }^{29}$ Incremental Fit Index (IFI) values range between 0 and 1 with values close to 1 indicating a well fitted model (Arbuckle and Wothke 1995). 
is consistent with the norm for its industry. Scale endpoints are 0 denoting much lower than the norm and 10 denoting much higher than the norm. Consistent with expectations, more committed disclosers are viewed as norm-inconsistent and less committed disclosers are viewed as norm-consistent. That is, the relationship between commitment to disclosure and perceptions of norm-consistency (Link 1) is negative and significant ( $\mathrm{t}$ $=-3.97, \mathrm{p}<.01)$. Next, consistent with the idea that participants will react more strongly to an outcome if it is norm-inconsistent than if it is norm-consistent, I expect that the relationship between perceptions of norm consistency and managers' forecast credibility (Link 2) will be moderated by prior forecast accuracy. As expected, there is a significant interaction between perceptions of norm consistency and prior forecast accuracy on managers' reporting credibility $\left(\chi_{1}^{2}=7.29, \mathrm{p}<.01\right)$. The effect of perceptions of normconsistency, albeit significant for both high and low accuracy, works in opposite directions (Link 3: High accuracy $\mathrm{t}=-.1 .64, \mathrm{p}=.05$; Low accuracy $\mathrm{t}=2.51, \mathrm{p}<.01$ ) which is consistent with the interaction between commitment to disclosure and prior forecast accuracy reported earlier. Finally, as expected, I find a positive relationship between perceptions of managers' forecasting credibility and participants' P/E judgments $($ Link 3: $\mathrm{t}=2.76, \mathrm{p}<.01)$.

Of the three proposed mechanisms (risk-based, decision-based, and norm-based) by which commitment to disclosure and prior forecast accuracy impact managers' forecast credibility, I find the strongest support for the norm-based mechanism. This result suggests that people's perceptions of actions and decisions may not always coincide, thus contradicting a common assumption in the omission bias literature (Niedermayer and Chapman 2001, Kordes-de Vaal 1996). Instead, in settings such as the voluntary disclosure context in which the present study is set - people appear to be 
evaluating actions based on whether they appear to be consistent with norms or not and their eventual judgments appear to be related to perceptions of norm-consistency. 
Table 1: Judgments of Managers' Trustworthiness

Panel A: Mean Judgments (Standard Deviation)

\begin{tabular}{|l|c|c|c|}
\hline \multicolumn{4}{|c|}{ Initial Judgments } \\
\hline \multicolumn{4}{|c|}{ Accuracy } \\
\hline $\begin{array}{l}\text { Commitment } \\
\text { to Disclosure }\end{array}$ & $\begin{array}{c}\text { Low } \\
\text { Accuracy }\end{array}$ & $\begin{array}{c}\text { High } \\
\text { Accuracy }\end{array}$ & $\begin{array}{c}\text { Row } \\
\text { Means }\end{array}$ \\
\hline Less & 6.88 & 6.58 & 6.73 \\
Committed & $\begin{array}{c}1.52) \\
\mathrm{n}=23\end{array}$ & $\begin{array}{c}(1.67) \\
\mathrm{n}=23\end{array}$ & $\begin{array}{c}1.58) \\
\mathrm{n}=46\end{array}$ \\
\hline $\begin{array}{l}\text { More } \\
\text { Committed }\end{array}$ & $\begin{array}{c}6.22 \\
(1.48)\end{array}$ & $\begin{array}{c}6.08 \\
(1.39)\end{array}$ & $\begin{array}{c}6.15 \\
(1.42)\end{array}$ \\
& $\mathrm{n}=23$ & $\mathrm{n}=24$ & $\mathrm{n}=47$ \\
\hline $\begin{array}{l}\text { Column } \\
\text { Means }\end{array}$ & $\begin{array}{c}6.55 \\
(1.52) \\
\mathrm{n}=46\end{array}$ & $\begin{array}{c}6.32 \\
(1.54)\end{array}$ & \\
& $\mathrm{n}=47$ & \\
\hline
\end{tabular}

\begin{tabular}{|c|c|c|c|}
\hline \multicolumn{4}{|c|}{ Final Judgments } \\
\hline \multicolumn{4}{|c|}{ Accuracy } \\
\hline $\begin{array}{l}\text { Commitment } \\
\text { to Disclosure }\end{array}$ & $\begin{array}{c}\text { Low } \\
\text { Accuracy }\end{array}$ & $\begin{array}{c}\text { High } \\
\text { Accuracy }\end{array}$ & $\begin{array}{c}\text { Row } \\
\text { Means }\end{array}$ \\
\hline $\begin{array}{l}\text { Less } \\
\text { Committed }\end{array}$ & $\begin{array}{c}4.91 \\
(1.72) \\
\mathrm{n}=23\end{array}$ & $\begin{array}{c}5.92 \\
(2.07) \\
\mathrm{n}=23\end{array}$ & $\begin{array}{c}5.41 \\
(1.95) \\
n=46\end{array}$ \\
\hline $\begin{array}{l}\text { More } \\
\text { Committed }\end{array}$ & $\begin{array}{c}3.54 \\
(2.11) \\
\mathrm{n}=23\end{array}$ & $\begin{array}{c}7.52 \\
(1.61) \\
\mathrm{n}=24\end{array}$ & $\begin{array}{c}5.57 \\
(2.23) \\
\mathrm{n}=47\end{array}$ \\
\hline $\begin{array}{l}\text { Column } \\
\text { Means }\end{array}$ & $\begin{array}{c}4.23 \\
(2.03) \\
\mathrm{n}=46\end{array}$ & $\begin{array}{c}6.74 \\
(1.99) \\
\mathrm{n}=47\end{array}$ & \\
\hline
\end{tabular}

Participants provide their initial judgments of managers' trustworthiness based on background information about a hypothetical company. Following their initial judgments, the two independent variables in the study - commitment to disclosure and prior forecast accuracy are varied at two levels: high and low, resulting in four conditions. Participants then provide their revised (final) judgments of managers' trustworthiness. Scale endpoints are 0 ("Not at all trustworthy") and 10 ("Highly trustworthy"). Panel A presents these initial and final judgments. 
Table 1: Judgments of Managers' Trustworthiness (Continued)

Pane B: Analysis of Covariance for Final Trustworthiness Judgments

\begin{tabular}{|l|r|r|r|r|}
\hline Source & \multicolumn{1}{c|}{$\begin{array}{c}\text { Sums of } \\
\text { Squares }\end{array}$} & \multicolumn{1}{c|}{$d f$} & F-Statistic & $p$-value \\
\hline Initial Trustworthiness Judgment (Covariate) & 39.75 & 1 & 12.64 & $<.001$ \\
\hline Commitment to Disclosure & 3.05 & 1 & 0.97 & .327 \\
\hline Prior Forecaster Accuracy & 154.87 & 1 & 49.26 & $<.001$ \\
\hline Commitment $\times$ Prior Forecaster accuracy & 48.53 & 1 & 15.44 & $<.001$ \\
\hline
\end{tabular}

Panel C: Simple Main Effects

\begin{tabular}{|l|l|l|l|}
\hline $\begin{array}{l}\text { Commitment to } \\
\text { Disclosure }\end{array}$ & $d f$ & F-stat & p-value \\
\hline $\begin{array}{l}\text { Effect of more vs. } \\
\text { less commitment to } \\
\text { disclosure at low } \\
\text { accuracy }\end{array}$ & 1 & 4.13 & .023 \\
\hline $\begin{array}{l}\text { Effect of more vs. } \\
\text { less commitment to } \\
\text { disclosure at high } \\
\text { accuracy }\end{array}$ & 1 & 12.13 & $<.001$ \\
\hline
\end{tabular}

Panel D: Simple Main Effects

\begin{tabular}{|l|l|l|l|}
\hline Accuracy & $d f$ & F-stat & p-value \\
\hline $\begin{array}{l}\text { Effect of high vs. } \\
\text { low accuracy when } \\
\text { managers are less } \\
\text { committed }\end{array}$ & 1 & 4.75 & .016 \\
\hline $\begin{array}{l}\text { Effect of high vs. } \\
\text { low accuracy when } \\
\text { managers are more } \\
\text { committed }\end{array}$ & 1 & 60.72 & $<.001$ \\
\hline
\end{tabular}

Panel B presents the results of an analysis of covariance with final trustworthiness judgments as the dependent variable, initial trustworthiness judgments as the covariate, commitment to disclosure and prior forecaster accuracy as the independent variables. All reported p-values are two-tailed.

Panels $\mathrm{C}$ and D present the simple main effect of each independent variable at levels of the other independent variable. All reported p-values are one-tailed. 
Table 2: Judgments of Managers' Forecasting Competence

Panel A: Mean Judgments (Standard Deviation)

\begin{tabular}{|l|c|c|c|}
\hline \multicolumn{4}{|c|}{ Initial Judgments } \\
\hline \multicolumn{4}{|c|}{ Accuracy } \\
\hline $\begin{array}{l}\text { Commitment } \\
\text { to Disclosure }\end{array}$ & $\begin{array}{c}\text { Low } \\
\text { Accuracy }\end{array}$ & $\begin{array}{c}\text { High } \\
\text { Accuracy }\end{array}$ & $\begin{array}{c}\text { Row } \\
\text { Means }\end{array}$ \\
\hline Less & 5.67 & 5.47 & 5.57 \\
Committed & $\begin{array}{c}(1.72) \\
\mathrm{n}=23\end{array}$ & $\begin{array}{c}(1.60) \\
\mathrm{n}=23\end{array}$ & $\begin{array}{c}(1.64) \\
\mathrm{n}=46\end{array}$ \\
\hline & 5.14 & 5.23 & 5.19 \\
More & $(1.37)$ & $\begin{array}{c}(1.95) \\
\mathrm{n}=24\end{array}$ & $\mathrm{n}=47$ \\
Committed & $\mathrm{n}=23$ & $\mathrm{n}$ & \\
\hline Column & 5.40 & 5.35 & \\
Means & $\begin{array}{c}1.56) \\
\mathrm{n}=46\end{array}$ & $\begin{array}{c}(1.77) \\
\mathrm{n}=47\end{array}$ \\
\hline
\end{tabular}

\begin{tabular}{|c|c|c|c|}
\hline \multicolumn{4}{|c|}{ Final Judgments } \\
\hline \multicolumn{4}{|c|}{ Accuracy } \\
\hline $\begin{array}{l}\text { Commitment } \\
\text { to Disclosure }\end{array}$ & $\begin{array}{c}\text { Low } \\
\text { Accuracy }\end{array}$ & $\begin{array}{c}\text { High } \\
\text { Accuracy }\end{array}$ & $\begin{array}{c}\text { Row } \\
\text { Means }\end{array}$ \\
\hline $\begin{array}{l}\text { Less } \\
\text { Committed }\end{array}$ & $\begin{array}{c}3.35 \\
(1.86) \\
\mathrm{n}=23\end{array}$ & $\begin{array}{c}6.75 \\
(1.63) \\
n=23\end{array}$ & $\begin{array}{c}5.05 \\
(2.44) \\
\mathrm{n}=46\end{array}$ \\
\hline $\begin{array}{l}\text { More } \\
\text { Committed }\end{array}$ & $\begin{array}{c}2.27 \\
(1.50) \\
\mathrm{n}=23\end{array}$ & $\begin{array}{c}8.12 \\
(1.27) \\
\mathrm{n}=24\end{array}$ & $\begin{array}{c}5.26 \\
(3.26) \\
\mathrm{n}=47\end{array}$ \\
\hline $\begin{array}{l}\text { Column } \\
\text { Means }\end{array}$ & $\begin{array}{c}2.81 \\
(1.75) \\
n=46\end{array}$ & $\begin{array}{c}7.45 \\
(1.60) \\
n=47\end{array}$ & \\
\hline
\end{tabular}

Participants provide their initial judgments of managers' forecasting competence based on background information about a hypothetical company. Following their initial judgments, the two independent variables in the study - commitment to disclosure and prior forecast accuracy are varied at two levels: high and low, resulting in four conditions. Participants then provide their revised (final) judgments of managers' forecasting competence. Scale endpoints are 0 ("Not at all competent") and 10 ("Highly competent"). Panel A presents these initial and final judgments. 
Table 2: Judgments of Managers’ Forecasting Competence (Continued)

Pane B: Analysis of Covariance for Final Competence Judgments

\begin{tabular}{|l|l|l|l|l|}
\hline Source & $\begin{array}{c}\text { Sums of } \\
\text { Squares }\end{array}$ & $d f$ & F-Statistic & $p$-value \\
\hline Initial Competence Judgment (Covariate) & 40.49 & 1 & 19.78 & $<.001$ \\
\hline Commitment to Disclosure & 2.08 & 1 & 1.01 & .317 \\
\hline Prior Forecaster Accuracy & 501.58 & 1 & 245.01 & $<.001$ \\
\hline Commitment $\times$ Prior Forecaster accuracy & 31.61 & 1 & 15.44 & $<.001$ \\
\hline
\end{tabular}

Panel C: Simple Main Effects

\begin{tabular}{|l|l|l|l|}
\hline $\begin{array}{l}\text { Commitment to } \\
\text { Disclosure }\end{array}$ & $d f$ & F-stat & p-value \\
\hline $\begin{array}{l}\text { Effect of more vs. } \\
\text { less commitment to } \\
\text { disclosure at low } \\
\text { accuracy }\end{array}$ & 1 & 4.16 & .022 \\
\hline $\begin{array}{l}\text { Effect of more vs. } \\
\text { less commitment to } \\
\text { disclosure at high } \\
\text { accuracy }\end{array}$ & 1 & 12.33 & $<.001$ \\
\hline
\end{tabular}

Panel D: Simple Main Effects

\begin{tabular}{|l|l|l|l|}
\hline Accuracy & $d f$ & F-stat & p-value \\
\hline $\begin{array}{l}\text { Effect of high vs. } \\
\text { low accuracy when } \\
\text { managers are less } \\
\text { committed }\end{array}$ & 1 & 67.86 & $<.001$ \\
\hline $\begin{array}{l}\text { Effect of high vs. } \\
\text { low accuracy when } \\
\text { managers are more } \\
\text { committed }\end{array}$ & 1 & 193.80 & $<.001$ \\
\hline
\end{tabular}

Panel B presents the results of an analysis of covariance with final competence judgments as the dependent variable, initial competence judgments as the covariate, commitment to disclosure and prior forecaster accuracy as the independent variables. All reported pvalues are two-tailed.

Panels $C$ and D present the simple main effect of each independent variable at levels of the other independent variable. All reported p-values are one-tailed. 
Table 3: Judgments of Managers' Forecasting Credibility

Panel A: Mean Judgments (Standard Deviation)

\begin{tabular}{|l|c|c|c|}
\hline \multicolumn{4}{|c|}{ Initial Judgments } \\
\hline \multicolumn{4}{|c|}{ Accuracy } \\
\hline $\begin{array}{l}\text { Commitment } \\
\text { to Disclosure }\end{array}$ & $\begin{array}{c}\text { Low } \\
\text { Accuracy }\end{array}$ & $\begin{array}{c}\text { High } \\
\text { Accuracy }\end{array}$ & $\begin{array}{c}\text { Row } \\
\text { Means }\end{array}$ \\
\hline $\begin{array}{l}\text { Less } \\
\text { Committed }\end{array}$ & $\begin{array}{c}5.93 \\
(1.61) \\
\mathrm{n}=23\end{array}$ & $\begin{array}{c}5.88 \\
(1.66) \\
\mathrm{n}=23\end{array}$ & $\begin{array}{c}5.90 \\
(1.62) \\
\mathrm{n}=46\end{array}$ \\
\hline $\begin{array}{l}\text { More } \\
\text { Committed }\end{array}$ & $\begin{array}{c}5.75 \\
\mathrm{n}=23\end{array}$ & $\begin{array}{c}5.68 \\
(1.40)\end{array}$ & $\begin{array}{c}5.72 \\
\mathrm{n}=24\end{array}$ \\
& $\mathrm{n}=47$ \\
Column & 5.83 & 5.78 & \\
Means & $\begin{array}{c}1.46) \\
\mathrm{n}=46\end{array}$ & $\begin{array}{c}(1.52) \\
\mathrm{n}=47\end{array}$ \\
\hline
\end{tabular}

\begin{tabular}{|l|c|c|c|}
\hline \multicolumn{4}{|c|}{ Final Judgments } \\
\hline \multicolumn{4}{|c|}{ Accuracy } \\
\hline $\begin{array}{l}\text { Commitment } \\
\text { to Disclosure }\end{array}$ & $\begin{array}{c}\text { Low } \\
\text { Accuracy }\end{array}$ & $\begin{array}{c}\text { High } \\
\text { Accuracy }\end{array}$ & $\begin{array}{c}\text { Row } \\
\text { Means }\end{array}$ \\
\hline Less & 3.70 & 6.62 & 5.16 \\
Committed & $\begin{array}{c}(1.66) \\
\mathrm{n}=23\end{array}$ & $\begin{array}{c}(1.80) \\
\mathrm{n}=23\end{array}$ & $\begin{array}{c}(2.26) \\
\mathrm{n}=46\end{array}$ \\
\hline More & $\begin{array}{c}2.78 \\
(1.66)\end{array}$ & $\begin{array}{c}7.83 \\
(1.63)\end{array}$ & $\begin{array}{c}5.36 \\
(3.02) \\
\mathrm{n}=24\end{array}$ \\
$\mathrm{n}=23$ & $\mathrm{n}=47$ \\
\hline $\begin{array}{l}\text { Column } \\
\text { Means }\end{array}$ & $\begin{array}{c}3.24 \\
(1.71)\end{array}$ & $\begin{array}{c}7.24 \\
(1.80) \\
\mathrm{n}=46\end{array}$ & \\
\hline
\end{tabular}

Participants provide their initial judgments of managers' forecasting credibility based on background information about a hypothetical company. Following their initial judgments, the two independent variables in the study - commitment to disclosure and prior forecast accuracy are varied at two levels: high and low, resulting in four conditions. Participants then provide their revised (final) judgments of managers' forecasting credibility. Scale endpoints are 0 ("Not at all credible") and 10 ("Highly credible"). Panel A presents these initial and final judgments. 
Table 3: Judgments of Managers' Forecasting Credibility (Continued)

Pane B: Analysis of Covariance for Final Credibility Judgments

\begin{tabular}{|l|l|l|l|l|}
\hline Source & $\begin{array}{l}\text { Sums of } \\
\text { Squares }\end{array}$ & $d f$ & F-Statistic & $p$-value \\
\hline Initial Credibility Judgment (Covariate) & 18.97 & 1 & 7.11 & .009 \\
\hline Commitment to Disclosure & 1.00 & 1 & 0.38 & .541 \\
\hline Prior Forecaster Accuracy & 372.50 & 1 & 139.68 & $<.001$ \\
\hline Commitment $\times$ Prior Forecaster accuracy & 26.50 & 1 & 9.94 & .002 \\
\hline
\end{tabular}

Panel C: Simple Main Effects

\begin{tabular}{|l|l|l|l|}
\hline $\begin{array}{l}\text { Commitment to } \\
\text { Disclosure }\end{array}$ & $d f$ & F-stat & p-value \\
\hline $\begin{array}{l}\text { Effect of more vs. } \\
\text { less commitment to } \\
\text { disclosure at low } \\
\text { accuracy }\end{array}$ & 1 & 3.18 & .039 \\
\hline $\begin{array}{l}\text { Effect of more vs. } \\
\text { less commitment to } \\
\text { disclosure at high } \\
\text { accuracy }\end{array}$ & 1 & 7.15 & $<.001$ \\
\hline
\end{tabular}

Panel D: Simple Main Effects

\begin{tabular}{|l|l|l|l|}
\hline Accuracy & $d f$ & F-stat & p-value \\
\hline $\begin{array}{l}\text { Effect of high vs. } \\
\text { low accuracy when } \\
\text { managers are less } \\
\text { committed }\end{array}$ & 1 & 37.18 & $<.001$ \\
\hline $\begin{array}{l}\text { Effect of high vs. } \\
\text { low accuracy when } \\
\text { managers are more } \\
\text { committed }\end{array}$ & 1 & 113.26 & $<.001$ \\
\hline
\end{tabular}

Panel B presents the results of an analysis of covariance with final credibility judgments as the dependent variable, initial credibility judgments as the covariate, commitment to disclosure and prior forecaster accuracy as the independent variables. All reported pvalues are two-tailed.

Panels $C$ and D present the simple main effect of each independent variable at levels of the other independent variable. All reported p-values are one-tailed. 
Table 4: Judgments of Disclosure Credibility

Panel A: Mean Judgments (Standard Deviation)

\begin{tabular}{|l|c|c|c|}
\hline \multicolumn{4}{|c|}{ Judgments of Disclosure Credibility } \\
\hline \multicolumn{4}{|c|}{ Accuracy } \\
\hline $\begin{array}{l}\text { Commitment } \\
\text { to Disclosure }\end{array}$ & $\begin{array}{c}\text { Low } \\
\text { Accuracy }\end{array}$ & $\begin{array}{c}\text { High } \\
\text { Accuracy }\end{array}$ & $\begin{array}{c}\text { Row } \\
\text { Means }\end{array}$ \\
\hline Less & 3.75 & 6.14 & 5.54 \\
Committed & $\begin{array}{c}(1.92) \\
\mathrm{n}=23\end{array}$ & $\begin{array}{c}(2.03) \\
\mathrm{n}=23\end{array}$ & $\begin{array}{c}(2.69) \\
\mathrm{n}=46\end{array}$ \\
\hline & 3.35 & 7.64 & 4.94 \\
More & $(1.77)$ & $(1.43)$ & $(2.30)$ \\
Committed & $\mathrm{n}=23$ & $\mathrm{n}=24$ & $\mathrm{n}=47$ \\
\hline Column & $\begin{array}{c}3.55 \\
(1.84)\end{array}$ & $\begin{array}{c}6.91 \\
(1.89)\end{array}$ \\
Means & $\mathrm{n}=46$ & $\mathrm{n}=47$ & \\
\hline
\end{tabular}

Participants are presented with an earnings forecast disclosure for an upcoming quarter for Zeta and asked to provide their assessment of the credibility of that disclosure. Response scale endpoints are 0 (not at all credible) and 10 (highly credible). The independent variables - commitment to disclosure and prior forecast accuracy are varied at two levels, high and low, resulting in four conditions. Participants are assigned to one of four conditions. Panel A presents participants' judgments by experimental condition. 
Table 4: Judgments Disclosure Credibility (Continued)

Pane B: Analysis of Variance for Disclosure Credibility Judgments

\begin{tabular}{|l|l|l|l|l|}
\hline Source & $\begin{array}{c}\text { Sums of } \\
\text { Squares }\end{array}$ & $D f$ & F-Statistic & $p$-value \\
\hline Commitment to Disclosure & 7.06 & 1 & 2.18 & .143 \\
\hline Prior Forecaster Accuracy & 259.68 & 1 & 80.20 & $<.001$ \\
\hline Commitment $\times$ Prior Forecaster accuracy & 21.03 & 1 & 6.50 & .013 \\
\hline
\end{tabular}

Panel B presents the results of an ANOVA with participants' disclosure credibility judgments as the dependent variable, commitment to disclosure and prior forecaster accuracy as the independent variables. All reported p-values are two-tailed. 
Table 5: Price-to-Earnings (P/E) Judgments

Panel A: Mean Judgments (Standard Deviation)

\begin{tabular}{|l|c|c|c|}
\hline \multicolumn{4}{|c|}{ Initial Judgments } \\
\hline \multicolumn{4}{|c|}{ Accuracy } \\
\hline $\begin{array}{l}\text { Commitment } \\
\text { to Disclosure }\end{array}$ & $\begin{array}{c}\text { Low } \\
\text { Accuracy }\end{array}$ & $\begin{array}{c}\text { High } \\
\text { Accuracy }\end{array}$ & $\begin{array}{c}\text { Row } \\
\text { Means }\end{array}$ \\
\hline Less & 19.70 & 19.02 & 19.38 \\
Committed & $\begin{array}{c}(3.20) \\
\mathrm{n}=23\end{array}$ & $\begin{array}{c}(2.50) \\
\mathrm{n}=21\end{array}$ & $\begin{array}{c}2.87) \\
\mathrm{n}=44\end{array}$ \\
\hline & 18.28 & 18.86 & 18.57 \\
More & $\begin{array}{c}(4.09) \\
\mathrm{n}=22\end{array}$ & $\begin{array}{c}1.93) \\
\mathrm{n}=22\end{array}$ & $\mathrm{n}=44$ \\
Committed & 19.00 & 18.94 & \\
\hline Column & $\begin{array}{c}(3.69) \\
\mathrm{n}=45\end{array}$ & $\begin{array}{c}(2.20) \\
\mathrm{n}=43\end{array}$ & \\
\hline
\end{tabular}

\begin{tabular}{|l|c|c|c|}
\hline \multicolumn{4}{|c|}{ Final Judgments } \\
\hline \multicolumn{4}{|c|}{ Accuracy } \\
\hline $\begin{array}{l}\text { Commitment } \\
\text { to Disclosure }\end{array}$ & $\begin{array}{c}\text { Low } \\
\text { Accuracy }\end{array}$ & $\begin{array}{c}\text { High } \\
\text { Accuracy }\end{array}$ & $\begin{array}{c}\text { Row } \\
\text { Means }\end{array}$ \\
\hline Less & 16.78 & 18.79 & 17.74 \\
Committed & $\begin{array}{c}(3.45) \\
\mathrm{n}=23\end{array}$ & $\begin{array}{c}(3.04) \\
\mathrm{n}=21\end{array}$ & $\begin{array}{c}(3.38) \\
\mathrm{n}=44\end{array}$ \\
\hline & 14.91 & 21.23 & 18.07 \\
More & $\begin{array}{c}(4.98) \\
(2.43)\end{array}$ & $\begin{array}{c}(5.02) \\
\mathrm{n}=44\end{array}$ \\
Committed & $\mathrm{n}=22$ & $\mathrm{n}=22$ & \\
\hline Column & 15.87 & 20.03 & \\
Means & $(4.33)$ & $(3.00)$ & \\
& $\mathrm{n}=45$ & $\mathrm{n}=43$ & \\
\hline
\end{tabular}

Participants provide their initial judgments of Zeta's $\mathrm{P} / \mathrm{E}$ based on background information and condensed financial statements for three years. Following their initial judgments, the two independent variables in the study - commitment to disclosure and prior forecast accuracy are varied at two levels: high and low, resulting in four conditions. Participants then provide their revised (final) P/E judgments. Participants are told that other firms in Zeta's industry trade at multiples of trailing earnings of between 15 and 25 times. Five participants provided P/E ratios that were unusable. Participants who provided $\mathrm{P} / \mathrm{E}$ ratios that were greater than 35 or lower than 5 were excluded from the analysis. This rule resulted in the exclusion of $\mathrm{P} / \mathrm{E}$ ratios provided by 5 participants. Therefore, the data reported in this table relate to 88 participants (93 participants less 5 unusable responses). 
Table 5: Price-to-Earnings (P/E) Judgments (Continued)

Panel B: Analysis of Covariance for Final P/E Judgments

\begin{tabular}{|l|l|l|l|l|}
\hline Source & $\begin{array}{c}\text { Sums of } \\
\text { Squares }\end{array}$ & $d f$ & F-Statistic & $p$-value \\
\hline Initial P/E Judgment (Covariate) & 504.02 & 1 & 71.04 & $<.001$ \\
\hline Commitment to Disclosure & 18.23 & 1 & 2.57 & .113 \\
\hline Prior Forecaster Accuracy & 386.74 & 1 & 54.51 & $<.001$ \\
\hline Commitment $\times$ Prior Forecaster accuracy & 59.29 & 1 & 8.36 & $<.005$ \\
\hline
\end{tabular}

Panel B presents the results of an analysis of covariance with final P/E judgments as the dependent variable, initial $\mathrm{P} / \mathrm{E}$ judgments as the covariate, commitment to disclosure and prior forecaster accuracy as the independent variables. All reported p-values are twotailed.

\section{Panel C: Simple Main Effects}

\begin{tabular}{|l|l|l|l|}
\hline $\begin{array}{l}\text { Commitment to } \\
\text { Disclosure }\end{array}$ & $d f$ & F-stat & p-value \\
\hline $\begin{array}{l}\text { Effect of more vs. } \\
\text { less commitment to } \\
\text { disclosure at low } \\
\text { accuracy }\end{array}$ & 1 & 0.83 & .185 \\
\hline $\begin{array}{l}\text { Effect of more vs. } \\
\text { less commitment to } \\
\text { disclosure at high } \\
\text { accuracy }\end{array}$ & 1 & 10.00 & $=.001$ \\
\hline
\end{tabular}

Panel D: Simple Main Effects

\begin{tabular}{|l|l|l|l|}
\hline Accuracy & $d f$ & F-stat & p-value \\
\hline $\begin{array}{l}\text { Effect of high vs. } \\
\text { low accuracy when } \\
\text { managers are less } \\
\text { committed }\end{array}$ & 1 & 9.95 & $=.001$ \\
\hline $\begin{array}{l}\text { Effect of high vs. } \\
\text { low accuracy when } \\
\text { managers are more } \\
\text { committed }\end{array}$ & 1 & 52.74 & $<.001$ \\
\hline
\end{tabular}

Panels C and D present the simple main effect of each independent variable at levels of the other independent variable. All reported p-values are one-tailed. 


\section{Figure 2: Managers' Forecasting Credibility: Normative Versus Omission Bias Perspective}

\begin{tabular}{|l|l|}
$\begin{array}{c}\text { Panel A: Joint Impact of Commitment to Disclosure and } \\
\text { Accuracy on Forecasting Credibility (Normative Perspective) }\end{array}$ \\
Panel A presents the prediction relating to the joint impact of \\
commitment to disclosure and prior forecast accuracy on perceptions \\
of managers forecasting credibility, based on the normative \\
perspective.
\end{tabular}




\section{Figure 3: Sequence of Experimental Procedures}

The experiment is administered in three parts. Participants respond to questions at the end of each part. Part A is common to all participants. That is, all participants see the same information. Following part A, participants are assigned to one of four conditions. The four conditions are obtained by crossing the two independent variables - managers' commitment to disclosure (more versus less committed) and managers' prior forecast accuracy (high versus low). In parts B and C, the information participants see depends on the condition they are assigned to, but the questions asked are identical across conditions.

\begin{tabular}{|c|c|}
\hline \multicolumn{2}{|c|}{ PART A (Background) } \\
\hline QUESTIONS ASKED & INFORMATION PROVIDED \\
\hline $\begin{array}{l}\text { Participants provide their assessment of } \\
\text { Zeta's managers with respect to } \\
\text { 1. Forecasting credibility } \\
\text { 2. Trustworthiness } \\
\text { 3. Forecasting competence } \\
\text { and a price to earnings multiple (P/E) for } \\
\text { valuing Zeta's shares. }\end{array}$ & $\begin{array}{l}\text { 1. Background information about Zeta } \\
\text { 2. Summary financials for Zeta }-3 \text { years } \\
\text { 3. General information about management earnings } \\
\text { forecasts } \\
\text { 4. Specific information about Zeta's management } \\
\text { earnings forecasts }\end{array}$ \\
\hline \multicolumn{2}{|c|}{ PART B (Manipulations) } \\
\hline QUESTIONS ASKED & INFORMATION PROVIDED \\
\hline Same as in part A & $\begin{array}{l}\text { MORE (LESS) COMMITTED CONDITION* } \\
\text { - Participants are told that Zeta's managers provided } \\
\text { quarterly earnings forecasts regularly (occasionally) } \\
\text { in the past three years. } \\
\text { HIGH (LOW) ACCURACY CONDITION* } \\
\text { - Participants are told that an independent rating } \\
\text { agency ranked Zeta's managers in the top (bottom) } \\
10 \% \text { of their industry with respect to forecast } \\
\text { accuracy. }\end{array}$ \\
\hline \multicolumn{2}{|c|}{ PART C (Follow up questions) } \\
\hline QUESTIONS ASKED & INFORMATION PROVIDED \\
\hline $\begin{array}{l}\text { Participants answer several questions } \\
\text { relating to the credibility of the earnings } \\
\text { forecast and their reasoning processes as } \\
\text { they worked through the information } \\
\text { presented to them. }\end{array}$ & Earnings forecast for the upcoming quarter \\
\hline
\end{tabular}

* Please see Appendices B through G for more detailed information and questions. 


\section{Figure 4: Graphical Summary of Results}

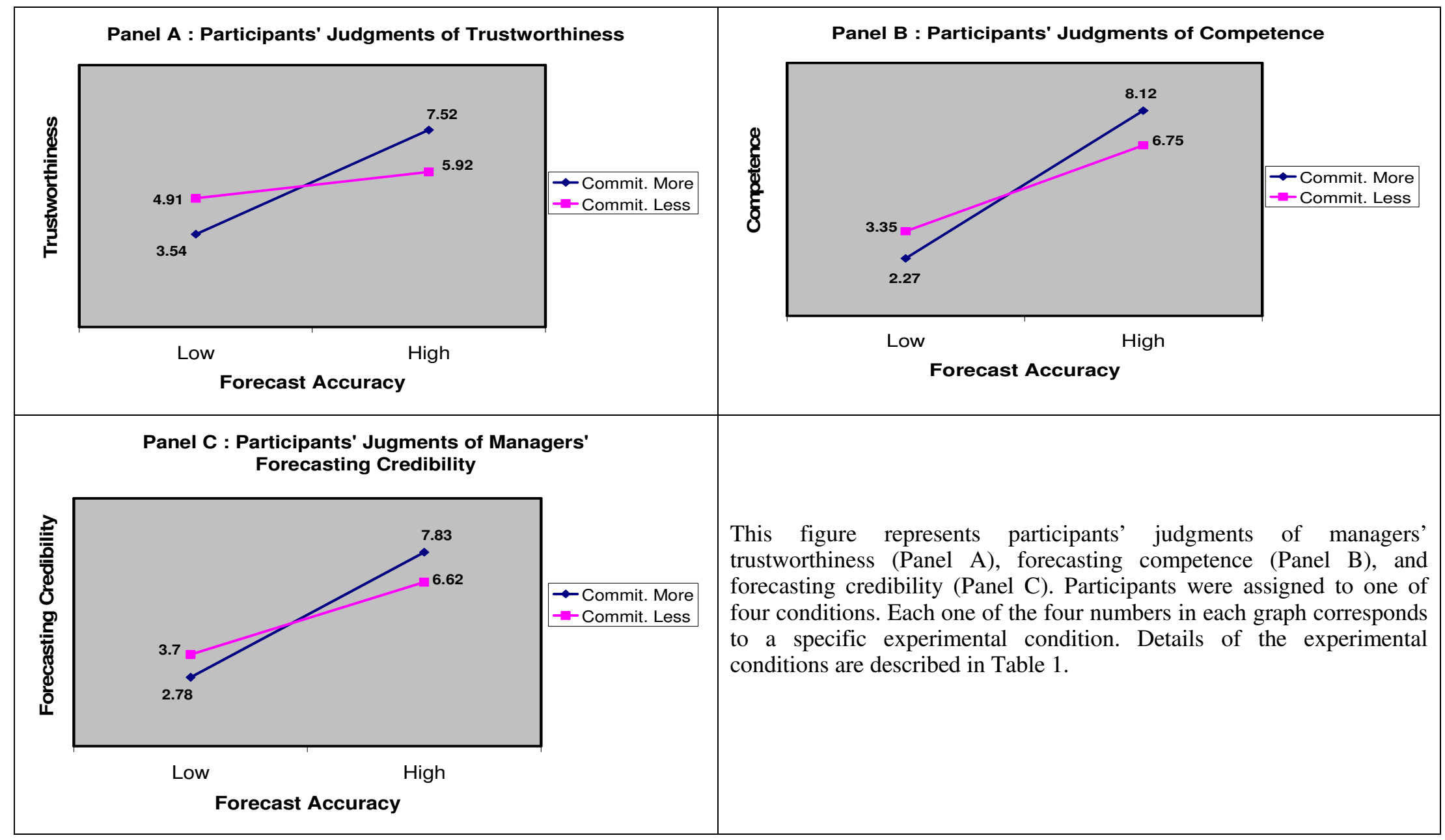




\title{
Figure 5: Structural Equation Model: Commitment to Disclosure and Perceptions of Norm-Consistency
}

\author{
Link $1(-)$ \\ Link $2(+/-)$ \\ Link $3(+)$
}

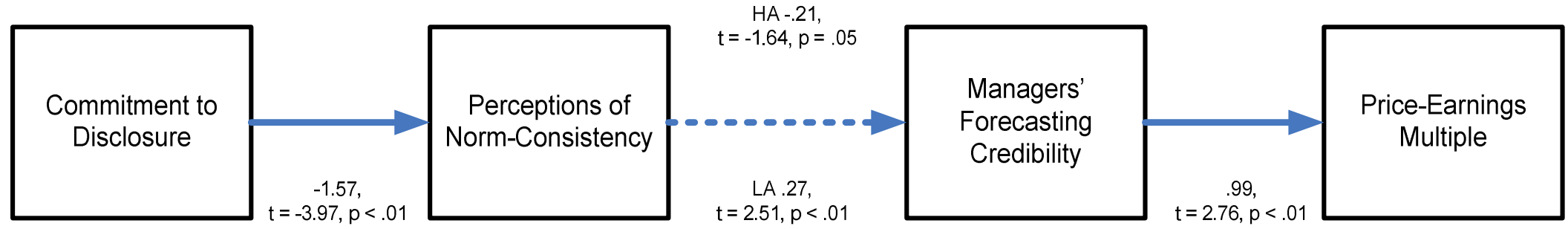

This figure shows the results of a structural-equations analysis that simultaneously estimates the relationships between my manipulated variables, mediating variable, and managers' forecasting credibility - my primary dependent variable. For a description of my the independent and dependent variables, please see Table 1. My mediating variable is participants' perceptions of norm-consistency. To obtain participants' perceptions of norm-consistency I ask them to rate whether Zeta's earnings forecast frequency is consistent with the norm for its industry. Scale endpoints are 0 denoting "much lower than the norm" and 10 denoting "much higher than the norm". Link 1 posits a negative relationship between commitment to disclosure and perceptions of norm-consistency. Link 2 posits a relationship between perceptions of norm consistency and managers' forecasting credibility that is expected to be moderated by prior forecast accuracy. Link 3 posits a positive relationship between managers' forecasting credibility and their firms' P/E multiple. Shown next to each link are unstandardized regression coefficients and corresponding t-statistics and p-values. I confirm the model's goodness of fit with a conventional $\chi^{2}$ test $\left(\chi_{13}^{2}=17.96, p=.16\right)$ and an incremental fit index (IFI) of 0.90 


\section{Chapter 4: Conclusion}

This paper experimentally examines the joint impact of commitment to disclosure and prior forecast accuracy on managers' forecasting credibility. I find that commitment to disclosure amplifies the impact of accuracy on investors' judgments of managers' credibility. That is, more committed forecasters are judged to be more credible relative to less committed forecasters, but only when prior forecast accuracy is high. In contrast, when prior forecast accuracy is low, more committed forecasters are judged to be less credible relative to their less committed peers. Although managers have expressed concerns about being viewed as less committed disclosers, the voluntary disclosure literature has not examined the credibility consequences of commitment to disclosure, either in isolation or jointly with other disclosure antecedents. Results of this study contribute to the voluntary disclosure literature by increasing our understanding of how disclosure antecedents interact to influence managers' forecasting credibility.

The study tests competing hypotheses about the joint impact of commitment to disclosure and prior forecast accuracy on managers' credibility based on economic theory as well as psychology theory. The findings in the study support the predictions based on

omission bias over those based on economic theory. One of the propositions in the omission bias literature is that because actions are more likely to be seen as decisions, people make stronger judgments based on action rather than inaction (Spranca and Baron 1991). Consistent with omission bias, managers who are more committed to disclosure are indeed seen as more active relative to less predictable forecasters. Participants, however, did not view that higher levels of action also correspond with higher levels of decision making. In fact, more committed (active) forecasters are seen as less engaged in decision-making, whereas less committed (active) forecasters are seen as more engaged 
in decision-making. In a management earnings forecast setting, managers who are more committed to disclosure (and therefore more active) may be viewed as routinely providing such forecasts. Therefore, acts of commission may be viewed as involving less deliberate decisions. In contrast, managers who are less committed to disclosure may be viewed as making a deliberate choice relating to the provision (or non-provision) of forecasts. Therefore, acts of omission may be viewed as more deliberate decisions.

Additional tests that examine how participants react to commitment to disclosure provide insight into an alternative mechanism by which commitment to disclosure influences credibility. Because management earnings forecasts are voluntary disclosures, managers who are more committed are viewed as acting above the norm, whereas managers who are less committed are viewed as acting in line with the norm. Participants appear to be distinguishing between more and less committed forecasters not along the lines of whether they represent active decision-making, but more along the lines of whether commitment represents norm-consistent versus norm-inconsistent behavior. Norm-inconsistent behaviors elicit much stronger reactions relative to norm-consistent behaviors for both positive and negative outcomes, which could explain the pattern of interaction observed between commitment to disclosure and accuracy.

The results of the study also provide one explanation for the apparent disconnect between what managers say and what they do with respect to commitment to disclosure. Although managers have a stated preference for being viewed as committed disclosers, this preference may not translate into actual disclosures because study participants in the role of investors appear to react strongly to behavior that is above and beyond the norm (high commitment to disclosure) compared to behavior that is in line with the norm (low commitment to disclosure). Participants' $\mathrm{P} / \mathrm{E}$ judgments suggest that commitment to disclosure could have adverse valuation consequences unless managers are also highly 
accurate. Therefore, managers who are tentative about accuracy may prefer to adhere to the norm rather than risk getting penalized if their forecast turns out to be inaccurate ex post.

The findings from this study should be interpreted subject to some limitations. First, participants are told that managers are either in the top 10 percent or the bottom 10 percent of their peer group with respect to accuracy. In real-world investment settings, information about managers' forecast accuracy (or commitment to disclosure) may not be so readily available. Second, for experimental considerations, I hold constant the specific content of the earnings forecast. Prior research, however suggests that managers widely vary forecast content on an annual or even quarterly basis (Hirst et al. 2007). To the extent that forecast content overrides considerations of accuracy or predictability, results of the study must be interpreted with caution. Finally, participants are provided only a limited set of information based on which they make their judgments. Whether additional information interacts systematically with the variables considered in this study is an open question.

Opportunities for future research come from two directions. First, this study examines commitment to disclosure in terms of disclosure versus non-disclosure of forecasts and abstracts away from the specific content of the disclosure. How investors would react if managers were unpredictable about the content of their disclosures (rather than the disclosure itself) remains an open question for future research. Second, results of this study suggest that investors' perceptions of trustworthiness and competence appear to be closely aligned across experimental conditions. Future research that investigates situations where trustworthiness judgments and competence judgments diverge (i.e., move in opposite directions) will help us better understand how participants combine those divergent factors in assessing managers' credibility. 


\section{APPENDICES}


APPENDIX A: COMMITMENT TO DISCLOSURE: ILLUSTRATION 


\section{Commitment to Disclosure: An Illustration}

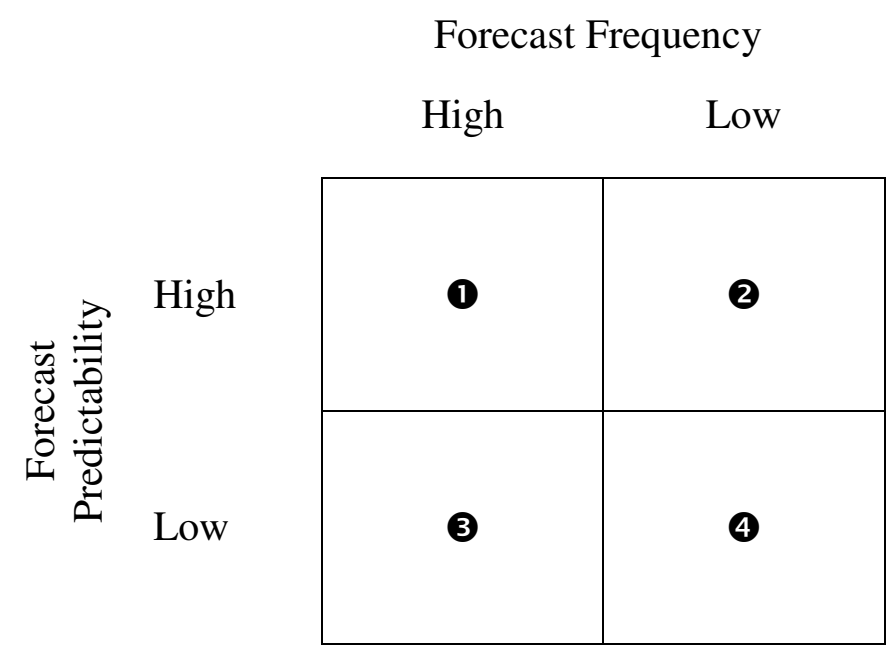

In the context of management earnings forecasts, I define commitment to disclosure as a combination of frequent and predictable forecasting. Thus, in my setting, more committed disclosers are those who provide earnings forecasts both frequently and predictably (cell ()). Less committed disclosers, in contrast, provide earnings forecasts neither frequently nor predictably (cell 4). Arguably, disclosure frequency and predictability co-vary in many natural settings. Defining the commitment to disclosure construct in terms of both disclosure frequency and disclosure predictability, thus, appropriately recognizes the multi-dimensional nature of the construct.

To illustrate these ideas, consider a firm and a three year time period. A firm in cell (1 may provide 12 earnings forecasts during this period (frequent) and may do so quarter after quarter (predictable). A firm in cell $\mathbf{4}$, in contrast, may provide only three forecasts during this entire three-year period (infrequent) and may do so in different quarters each year (unpredictable). Therefore, according to my definition, firms in cell $\mathbf{0}$ 
represent firms that are unambiguously more committed to disclosure whereas firms in cell 4 are unambiguously less committed to disclosure. Because the primary focus of this study is on understanding the consequences of commitment to disclosure, I focus on the cases where commitment to disclosure (or lack thereof) is clear.

I choose not to examine firms in cells $\mathbf{2}$ and $\mathbf{3}$ in this study for two reasons. First, manipulating predictability and frequency simultaneously, but in opposite directions weakens my manipulation of commitment to disclosure. By definition, firms that are high in forecast predictability, but low in forecast frequency (cell 2) will be viewed as less committed to disclosure. Similarly, firms that are high in forecast frequency, but low in forecast predictability (cell (4) will also be viewed as less committed to disclosure. Thus, in both cases, I weaken the manipulation of commitment to disclosure. Second, if I choose to manipulate either frequency or predictability (and am silent about the other), again, I will potentially reduce the strength of the commitment to disclosure manipulation. Information about disclosure frequency or predictability (with no details about the other) presents an incomplete picture based on which making inferences about commitment to disclosure will be difficult. Therefore, simultaneously varying both forecast frequency and forecast predictability in the same direction is critical to ensure the most powerful manipulation of the commitment to disclosure construct. 
APPENDIX B: EXPERIMENTAL MATERIALS 


\section{INSTRUCTIONS}

Thank you for participating in this study. The purpose of this study is to investigate how investors make judgments based on financial and non-financial information. There are no right or wrong answers to the questions you will be asked in this study. You should be able to complete this study in approximately 30 minutes.

For purposes of this study, assume that you are a potential investor evaluating the common stock of a company called Zeta. This study consists of three parts.

Part A contains selected financial information and background information about Zeta.

Parts B and C contain additional information about Zeta.

After each part, you will be asked to provide several judgments about Zeta and its management. The case information you will receive is not intended to include all the information that would be available if you were evaluating the common stock of Zeta. However, for purposes of this study, base your judgments on the information provided.

Should you have any questions during the study, please do not hesitate to ask. However, please do not discuss this study with other University of Texas students during the next two weeks. Discussing the study with others could invalidate the study.

Your input is very important to this study. Thank you again for your participation.

Shankar Venkataraman

PhD Candidate, Department of Accounting

McCombs School of Business

UNIVERSITY OF TEXAS AT AUSTIN 


\section{PART A}

\section{BACKGROUND INFORMATION}

Zeta, Inc. distributes heavy-duty pumps, power transmission equipment, electrical equipment, and other industrial supplies to the oil and gas, construction, and chemical industries. Zeta also provides services such as system design, fabrication, installation, repair and maintenance for companies in the construction industry. Zeta's business has grown steadily over the last five years. Zeta's stock trades on the NASDAQ.

\section{ZETA's EARNINGS HISTORY}

\begin{tabular}{|l|r|r|r|}
\hline Annual Income Statement & \multicolumn{3}{c|}{ (in \$ thousands except per share data) } \\
\hline Period Ended & $\mathbf{1 2 / 3 1 / 0 6}$ & $\mathbf{1 2 / 3 1 / 0 5}$ & $\mathbf{1 2 / 3 1 / 0 4}$ \\
Net Sales & 196,486 & 185,364 & 160,585 \\
\hline Gross Profit & 52,597 & 49,714 & 39,431 \\
\hline Net Income & 12,445 & 11,863 & 11,241 \\
Earnings per Share (EPS) & $\$ 1.13$ & $\$ 1.08$ & $\$ 1.02$ \\
\hline
\end{tabular}

\section{GENERAL INFORMATION ABOUT MANAGEMENT EARNINGS FORECASTS}

You obtained the following information about management earnings forecasts and about Zeta's management earnings forecasts from an online financial database.

- Managers are not legally required to provide earnings forecasts. In other words, management earnings forecasts are voluntary disclosures. Some companies are regular forecasters and some companies are not regular forecasters.

\section{INFORMATION ABOUT ZETA's PAST EARNINGS FORECASTS}

- Historically, Zeta's management earnings forecasts have included a mix of good news and bad news. That is, at times, the earnings forecasts provided by Zeta's managers have been higher than the market earnings expectations and at other times, the earnings forecasts provided by Zeta's managers have been lower than the market earnings expectations.

- On occasions when there have been forecast errors, these forecast errors have not been biased in one direction. That is, at times, the earnings forecasts provided by Zeta's managers have been higher than reported earnings and at other times, the earnings forecasts provided by Zeta's managers have been lower than reported earnings. 
APPENDIX C: PRE-MANIPULATION QUESTIONS 


\section{QUESTIONS - PART A}

Feel free to look at the case materials when answering the following questions. Assume that the date on which you are answering the questions is January $15^{\text {th }}, 2007$.

Please place a slash mark ( / ) on the point of the scale that corresponds to your judgment.

Answer all questions in the order they appear. After you have answered a question, please do not go back and change your response.

The questions below pertain to the credibility of Zeta's managers. In general, there are two dimensions to credibility - trustworthiness and competence. Below, I ask you about both of these dimensions. When responding to these questions, keep in mind that these two dimensions can, but do not necessarily, "move together". That is, for a given situation, trustworthiness and competence may both be judged high (or low). Alternatively, trustworthiness may be judged high when competence is judged high and vice versa. With these ideas in mind, please respond to the following questions.

1. I believe that Zeta's managers are with respect to their earnings forecasts.

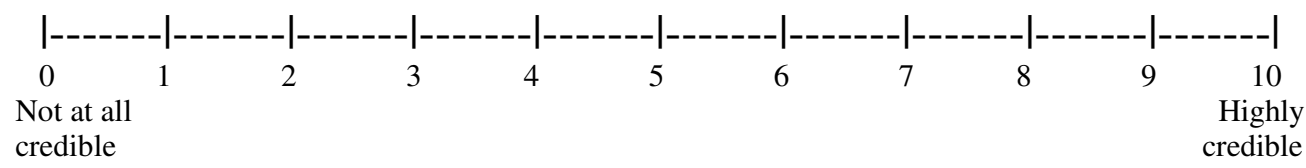

2. Based on Zeta's earnings forecasts, I believe that Zeta's managers are

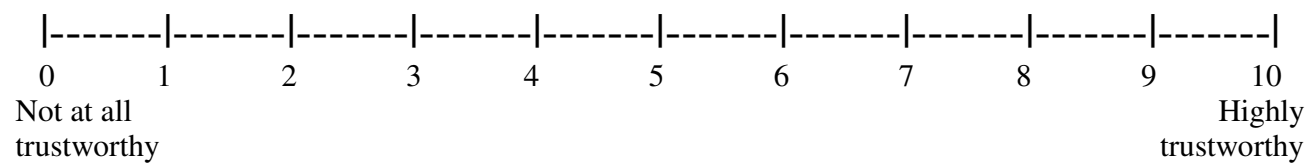

3. I believe that Zeta's managers are at forecasting earnings.

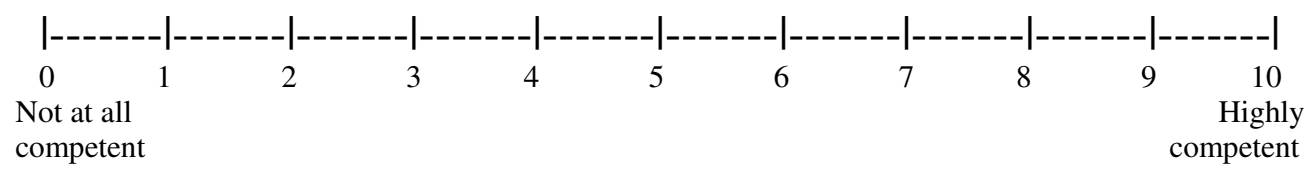




\section{Judgments about Zeta's Stock}

4. You decide to determine a fair price for Zeta's shares. To do this, assume that you think about the price - earnings (P/E) multiple that should be applied to Zeta's earnings for 2006. What would that number be?

Assume that other firms in Zeta's industry trade at multiples of trailing (i.e., prior year) earnings of between 15 and 25 times earnings.

NOTE: A low multiple means that you would not be willing to pay much for Zeta, while a high multiple means that you would be willing to pay more for Zeta.

$\mathrm{P} / \mathrm{E}=\quad \frac{}{\text { Fill in a P/E Multiple (number) here }}$ times 
APPENDIX D: MANIPULATIONS 


\section{High Commitment to Disclosure, High Accuracy Condition PART B}

\section{ADDITIONAL INFORMATION ABOUT ZETA}

You search for additional information about Zeta and find the following:

- Zeta's managers have provided quarterly earnings forecasts regularly in the past three years. Zeta provided twelve earnings forecasts in the years 2004, 2005, and 2006 (one in each quarter).

- An independent rating agency ranked Zeta's managers in the top $10 \%$ of their industry with respect to forecast accuracy. That is, in general, Zeta's earnings forecasts are highly accurate. 


\section{High Commitment to Disclosure, Low Accuracy Condition}

\section{PART B}

\section{ADDITIONAL INFORMATION ABOUT ZETA}

You search for additional information about Zeta and find the following:

- Zeta's managers have provided quarterly earnings forecasts regularly in the past three years. Zeta provided twelve earnings forecasts in the years 2004, 2005 , and 2006 (one in each quarter).

- An independent rating agency ranked Zeta's managers in the bottom $10 \%$ of their industry with respect to forecast accuracy. That is, in general, Zeta's earnings forecasts are not highly accurate. 


\section{Low Commitment to Disclosure, High Accuracy Condition}

\section{PART B}

\section{ADDITIONAL INFORMATION ABOUT ZETA}

You search for additional information about Zeta and find the following:

- Zeta's managers have provided quarterly earnings forecasts occasionally in the past three years. Zeta provided four forecasts over the past three years. In 2004, Zeta provided earnings forecasts in Q1 and Q4. In 2005, Zeta provided an earnings forecast in Q2 and in 2006, they provided one in Q3.

- An independent rating agency ranked Zeta's managers in the top $10 \%$ of their industry with respect to forecast accuracy. That is, in general, Zeta's earnings forecasts are highly accurate. 


\section{Low Commitment to Disclosure, Low Accuracy Condition PART B}

\section{ADDITIONAL INFORMATION ABOUT ZETA}

You search for additional information about Zeta and find the following:

- Zeta's managers have provided quarterly earnings forecasts occasionally in the past three years. Zeta provided four forecasts over the past three years. In 2004, Zeta provided earnings forecasts in Q1 and Q4. In 2005, Zeta provided an earnings forecast in Q2 and in 2006, they provided one in Q3.

- An independent rating agency ranked Zeta's managers in the bottom $10 \%$ of their industry with respect to forecast accuracy. That is, in general, Zeta's earnings forecasts are not highly accurate. 
APPENDIX E: POST-MANIPULATION QUESTIONS 


\section{QUESTIONS - PART B}

Answer the following questions based on all information you have about Zeta (i.e., Part A as well as Part B).

You are free to look at all previous case materials when answering the following questions.

Assume that the date on which you are answering the questions is January $15^{\text {th }}, 2007$.

Answer all questions in the order they appear. After you have answered a question, please do not go back and change your response.

1. I believe that Zeta's managers are with respect to their earnings forecasts.

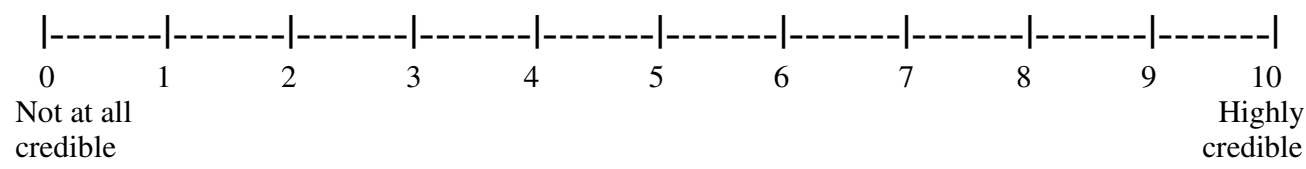

2. Based on Zeta's earnings forecasts, I believe that Zeta's managers are

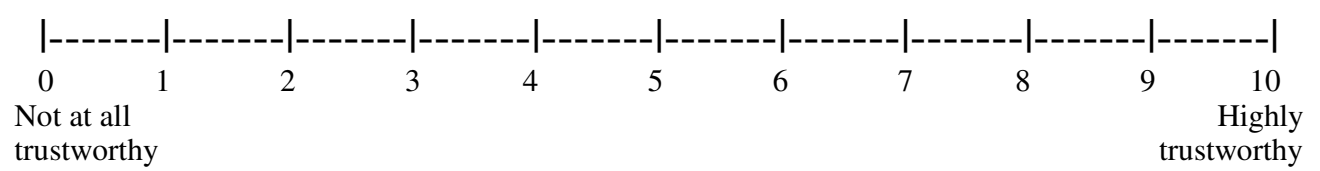

3. I believe that Zeta's managers are at forecasting earnings.

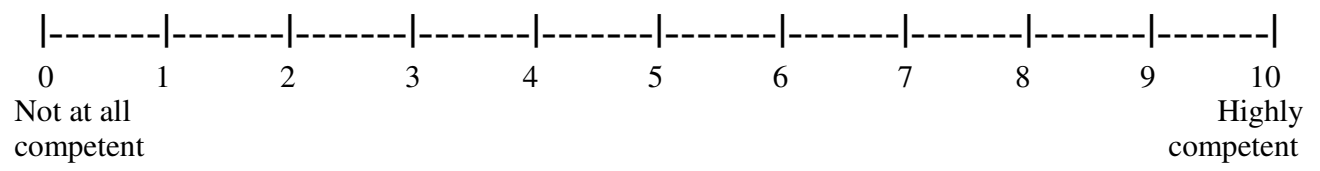




\section{Judgments about Zeta's Stock}

4. You decide to re-estimate the price - earnings (P/E) multiple that should be applied to Zeta's earnings for 2006 based on all information you now have. What would that number be?

Assume that other firms in Zeta's industry trade at multiples of trailing (i.e., prior year) earnings of between 15 and 25 times earnings.

NOTE: A low multiple means that you would not be willing to pay much for Zeta, while a high multiple means that you would be willing to pay more for Zeta.

$$
\mathrm{P} / \mathrm{E}=\frac{}{\text { Fill in a } P / E \text { Multiple (number) here }} \text { times }
$$

\section{PLEASE DO NOT TURN AHEAD TO PART C OF THIS STUDY UNTIL YOU COMPLETE THIS SECTION.}




\section{APPENDIX F: CURRENT EARNINGS FORECAST}




\section{PART C}

\section{ADDITIONAL INFORMATION ABOUT ZETA}

You obtain the following information about Zeta's earnings forecast from a column in the Wall Street Journal on January 15 ${ }^{\text {th }}, 2007$.

\section{THE WALL STREET JOURNAL.}

\section{Zeta Announces Earnings Forecast} for First Quarter of 2007

AUSTIN, TX. January 15, 2007- Zeta, Inc. today announced its earnings outlook for the first quarter of 2007. Zeta expects earnings per share (EPS) will be $\$ 0.31$ for the quarter ending March $31^{\text {st }}, 2007$. This estimate is 4 cents above the current consensus analyst EPS forecast of \$0.27. 
APPENDIX G: PROCESS-RELATED QUESTIONS 


\section{QUESTIONS - PART C}

Answer the following questions based on all information you have about Zeta

Assume that the date on which you are answering the questions is January $15^{\text {th }}, 2007$.

Please answer all questions assuming you are a potential investor in Zeta.

1. Based on the information available to me, I predict that Zeta's earnings per share (EPS) for the quarter ending $31^{\text {st }}$ March, 2007 will be $\$$

(Write in a number)

2. I believe that the earnings forecast provided by Zeta for the quarter ending $31^{\text {st }}$ March, 2007 is

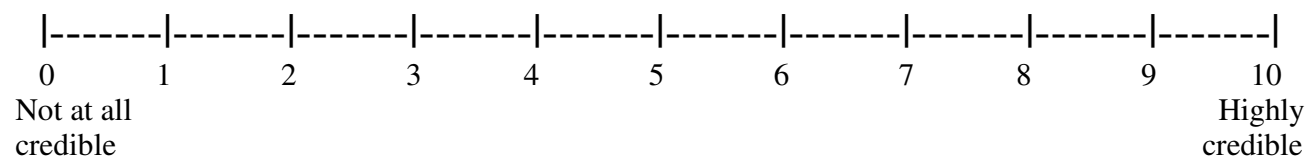

3. Zeta's track record of forecasting earnings makes me believe that Zeta's stock is relative to its peers.

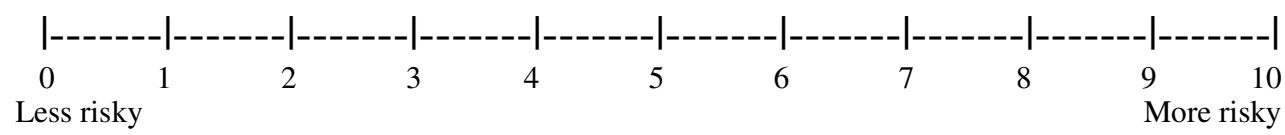

4. If I invest in Zeta's stock, I expect to spend in gathering additional information about Zeta to periodically monitor my investment.

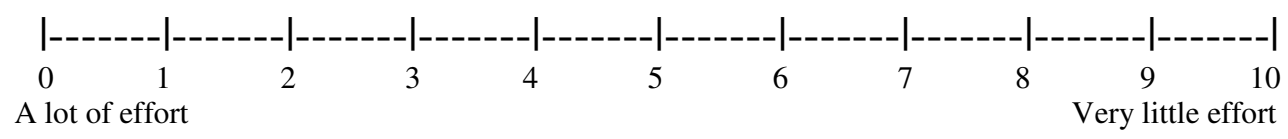

5. Based on the information in the case, I believe that Zeta's stock price is to be volatile.

likely

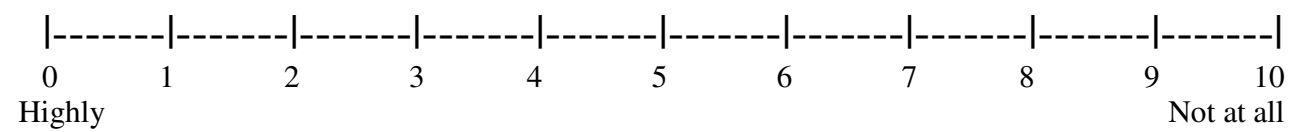


6. I believe that Zeta's earnings forecast history reflects on part of Zeta's managers.

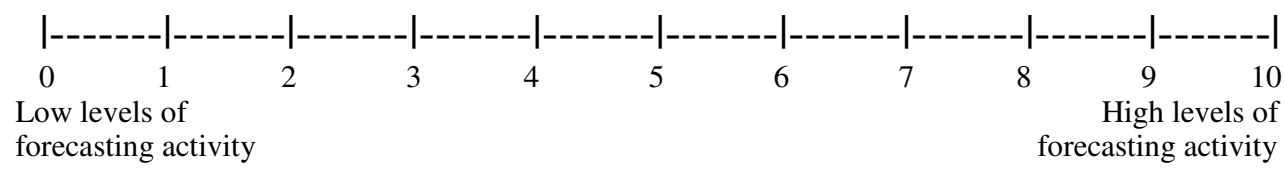

7. Based on Zeta's forecasting history, I believe that Zeta's managers choose whether or not to provide earnings forecasts every quarter after

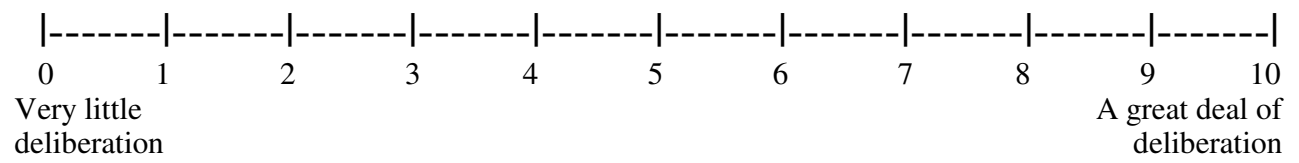

8. I believe that Zeta's earnings are to forecast.

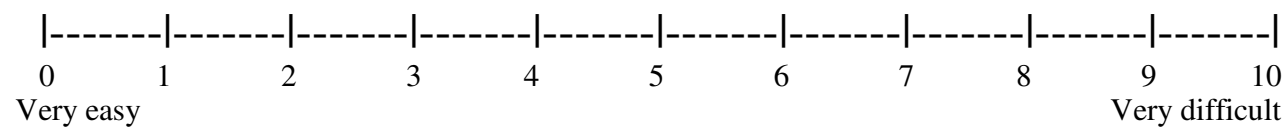

9. I believe that Zeta's earnings forecast frequency is than the norm for its industry.

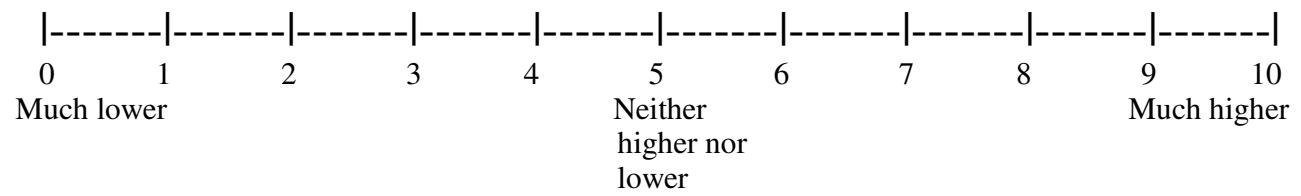

10. I believe that Zeta's managers' commitment to disclosure is relative to their peers.

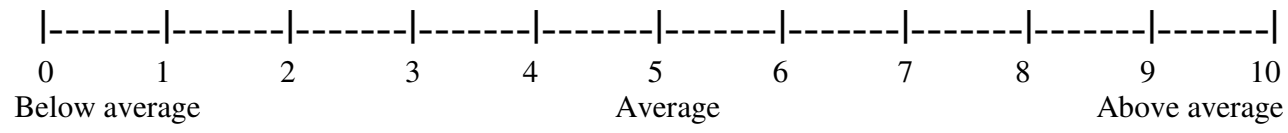

11. When Zeta's earnings for the first quarter of 2007 are reported, I expect that actual earnings will be than the forecast provided.

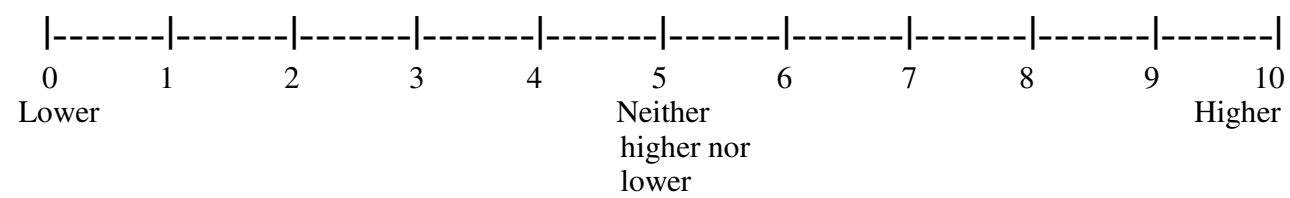




\section{Think about companies in general. The following questions do not pertain to Zeta.}

With that in mind, answer the following questions.

12. I believe that providing earnings forecasts on a regular basis reflects on managers' credibility.

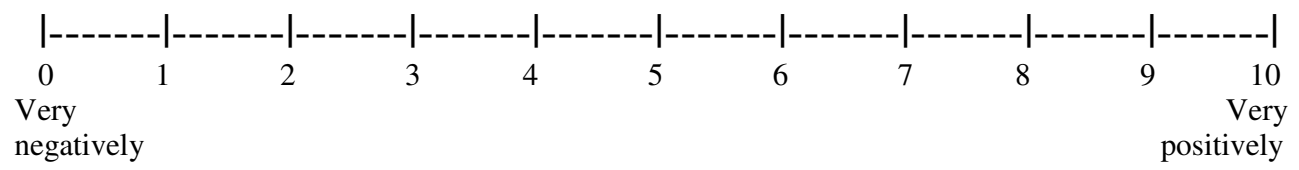

13. I believe that a history of accurate forecasts reflects credibility. on managers'

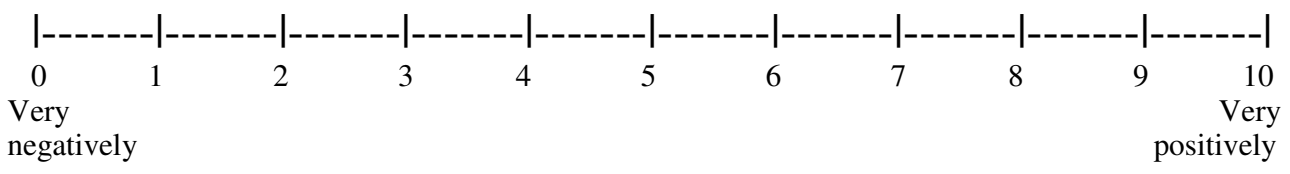

14. I believe that providing earnings forecasts on an irregular basis reflects on managers' credibility.

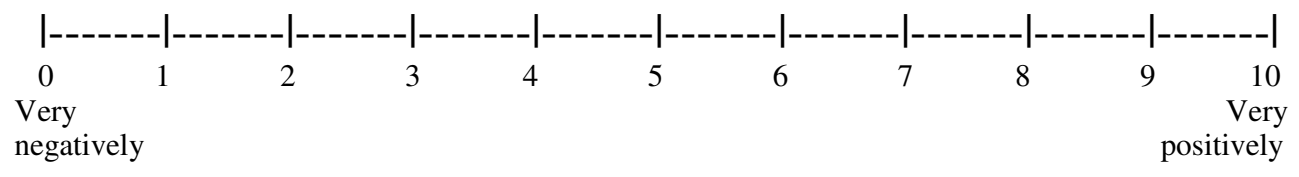

15. I believe that a history of inaccurate forecasts reflects on managers' credibility.

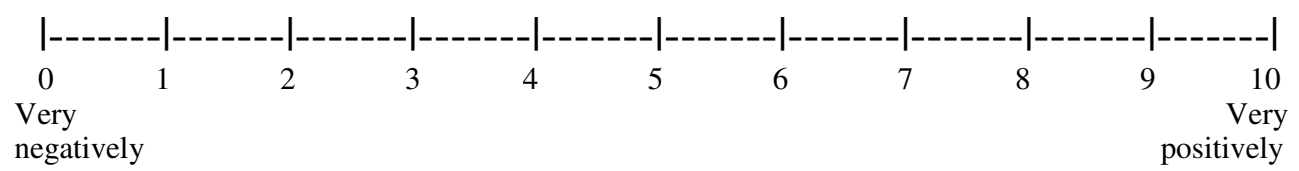




\section{Other Questions}

Please do not look back at the case materials when answering the following questions.

Note that the following questions pertain to Zeta.

1. Over the past 12 quarters, Zeta provided earnings forecasts (check one)

In all 12 quarters.

Only in 4 out of 12 quarters.

Cannot recall.

2. Zeta was rated by an independent rating agency to be (check one)

In the top $10 \%$ of its industry with respect to forecast accuracy.

In the bottom $10 \%$ of its industry with respect to forecast accuracy.

Cannot recall.

3. Zeta's forecast errors are mostly (check one)

Positive - Forecasts are mostly lower than reported earnings.

Negative - Forecasts are mostly higher than reported earnings.

Neutral - At times, Zeta's forecasts have been higher than reported earnings and at other times, the forecasts have been lower than reported earnings.

Cannot recall.

4. Zeta's earnings forecasts mostly conveyed (check one)

Good news - the forecasts provided by Zeta's managers have mostly been higher than market earnings expectations.

Bad news - the forecasts provided by Zeta's managers have mostly been lower than market earnings expectations.

A mix of good and bad news.

Cannot recall. 
IN ORDER TO UNDERSTAND WHY YOUR RESPONSES MIGHT DIFFER FROM THOSE OF

YOUR COLLEAGUES, PLEASE ANSWER THE FOLLOWING QUESTIONS.

1. Have you ever made investments in the common stock of a company? YES NO If yes, approximately how many times? times

2. Do you plan to invest in the common stock of a company at some time in the future?

YES NO

3. Have you ever made investments in a common stock mutual fund? YES NO

4. How many undergraduate and graduate finance and accounting courses have you taken, including those that you are taking this semester?

Finance

Accounting

5. How many years of full-time work experience do you have? years

6. Have you ever worked in the following capacities?

If yes, fill in the number of years. If no, leave blank.

Corporate finance years

Corporate Accounting years

Engineering, Operations, or other technical position years

Public Accounting years

Management years

Other years 


\section{References}

A.I.M.R. 2000. Corporate Disclosure Survey.

A.I.M.R. 2003. Member Survey of Global Corporate Financial Reporting Quality and Corporate Communications and Disclosure Practices.

Ajinkya, B., S. Bhojraj, and P. Sengupta. 2005. The Association between Outside Directors, Institutional Investors and the Properties of Management Earnings Forecasts. Journal of Accounting Research 43 (3): 343-376.

Anilowski, C., M. Feng, and D. Skinner. 2007. Does Earnings Guidance Affect Market Returns? The Nature and Information Content of Aggregate Earnings Guidance. Journal of Accounting and Economics 44: 36-63.

Arbuckle, J.L. and W. Wothke. 1995. Amos 4.0 User's Guide ; SmallWaters Corporation, Chicago, IL, 1995.

Atiase, R. K., H. Li, S. Supattarakul, and S. Tse. 2005. Market Reaction to Multiple Contemporaneous Earnings Signals: Earnings Announcements and Future Earnings Guidance. Review of Accounting Studies 10:497-525.

Atiase, R. K., S. Suppattarakul, and S. Tse. 2006. Price and Volume Reaction to Management Earnings Forecasts: The Incremental Effect of Managements' Prior Forecasting Reputation. Working Paper, University of Texas..

Baginski, S. P., and J. M. Hassell. 1990. The market interpretation of management earnings forecasts as a predictor of subsequent financial analyst forecast revision. The Accounting Review 65 (1): 175-90. 
Baron, J., and I. Ritov. 1994. Reference Points and Omission Bias. Organizational Behavior and Human Decision Processes 59: 475-498.

Barton, J., and M. Mercer. 2005. To Blame or Not to Blame: Analysts' Reactions to External Explanations for Poor Financial Performance. Journal of Accounting and Economics 39: 509-533.

Bhojraj, S., R. Libby, and H.Yang. 2008. Practice Makes Perfect: Do Firms and Markets Learn From Past Earnings Guidance Behavior? Working Paper, Cornell University

Botosan, C. A. 1997. Disclosure Level and the Cost of Equity Capital. The Accounting Review 72 (3): 323-349.

Botosan, C. A., and M. S. Harris. 2000. Motivations for a change in Disclosure Frequency and its Consequences: An Examination of Voluntary Segment Disclosures and its Consequences. Journal of Accounting Research 38 (2): 329353.

Brown, S., S. Hillegeist, and K. Lo. 2004. Conference Calls and Information Asymmetry. Journal of Accounting and Economics 37: 343-366.

Brown, L. D., and M. L. Caylor. 2005. A temporal analysis of quarterly earnings thresholds: Propensities and valuation consequences. The Accounting Review 80 (2): 423-40.

Chen, S. 2004. Why Do Managers Fail to Meet Their Own Forecasts? Working Paper, University of Washington. 
Cheng, M., K.R.Subramanyam, and Y. Zhang. 2005. Earnings Guidance and Managerial Myopia. Working Paper, University of Southern California.

Coller, M., and T. L. Yohn. 1997. Management Forecasts and Information Asymmetry: An Examination of Bid-Ask Spreads. Journal of Accounting Research 35 (2): $181-91$.

Cotter, J., I. Tuna, and P. Wysocki. 2006. Expectations Management and Beatable Targets: How Do Analysts React to Public Earnings Guidance? Contemporary Accounting Research 23 (3): 593-624.

Cunningham, J.B., and J. McGregor, (2000), "Trust and the Design of Work: Complementary Constructs in Satisfaction and Performance", Human Relations, Vol. 53 No.12, pp.1575-91

Diamond, D., and R. Verrecchia. 1991. Disclosure, Liquidity and the Cost of Capital. Journal of Finance 46: 1325-59.

Dye, R. 2001. An Evaluation of "Essays on Disclosure" and the Disclosure Literature in Accounting. Journal of Accounting and Economics 32: 181-235.

Easley, D., S. Hvidkjaer, and M. O'Hara. 2002. Is Information Risk a Determinant of Asset Returns? Journal of Finance LVII (5): 2185-2221.

Einhorn, H.J., and R.M. Hogarth. 1975. Unit Weighting Schemes for Decision Making. Organizational Behavior and Human Performance 13: 171-192.

Elliot, B.W., F.D. Hodge, J.J. Kennedy, and M. Pronk. 2007. Are M.B.A. Students a Good Proxy for Nonprofessional Investors? The Accounting Review 82 (1): 139168. 
Fogg, B.J., and H. Tseng. 1999. Credibility and Computing Technlogy. Communications of the ACM 42 (5): 39-44.

Frederickson, J. R., and J. S. Miller. 2004. The Effects of Pro Forma Earnings Disclosures on Analysts' and Nonprofessional Investors' Equity Valuation Judgments. The Accounting Review 79 (3): 667-686.

Graham, J., C. R. Harvey, and S. Rajagopal. 2005. The Economic Implications of Corporate Financial Reporting. Journal of Accounting and Economics 40: 3-73.

Hackenbrack, K. and M. Nelson. 1996. Auditors' Incentives and Their Application of Financial Accounting Standards. The Accounting Review 71 (1): 43-59.

Hassell, J. M., and R. H. Jennings. 1986. Relative Forecast Accuracy and the Timing of Earnings Forecast Announcements. The Accounting Review 61 (1): 58-75.

Hatcher, L. 1994. Using SAS for Factor Analysis and Structural Equation Modeling . Cary, NC: SAS Institute, Inc., 1994.

Hirst, D. E., L. Koonce, and J. Miller. 1999. The Joint Effect of Management's Prior Forecast Accuracy and the Form of Its Financial Forecasts on Investor Judgment. Journal of Accounting Research 37: 101-124.

Hirst, D. E., K. E. Jackson, and L. Koonce. 2003. Improving Financial Reports By Revealing the Accuracy of Prior Estimates. Contemporary Accounting Research 20 (1): 169-93.

Hirst, D. E., L. Koonce, and S. Venkataraman. 2008. Management Earnings Forecasts: A Review and Framework. Forthcoming, Accounting Horizons. 
Hobson, J.L., and S. Kachelmeier. 2005. Strategic Disclosure of Risky Prospects: A Laboratory Experiment. The Accounting Review 80 (3): 825-846.

Houston, J., B. Lev, and J. Tucker. 2006. To Guide or Not to Guide? Causes and Consequences of Stopping and Subsequently Resuming Earnings Guidance. Working paper, University of Florida.

Hribar, P., and H. Yang. 2006. CEO Overconfidence, Management Earnings Forecasts, and Earnings Management. Working Paper, Cornell University.

Hsieh, P., T. Koller, and S. R. Rajan. 2006. The Misguided Practice of Earnings Guidance. The McKinsey Quarterly Spring [ Web Supplement: McKinsey on Finance]: 1-6.

Hutton, A. P. 2005. Determinants of Managerial Earnings Guidance Prior to Regulation Fair Disclosure and Bias in Analysts' Earnings Forecasts. Contemporary Accounting Research 22 (4): 867-914.

Hutton, A., G. S. Miller, and D. J. Skinner. 2003. The Role of Supplementary Statements with Management Earnings Forecasts. Journal of Accounting Research 41 (5): 867-890.

Hutton, A., and P. Stocken. 2007. Effect of Reputation on the Credibility of Management Forecasts. Working Paper, Dartmouth College.

Jiambalvo, J., S. Rajgopal, and M. Venkatachalam. 2002. Institutional Ownership and the Extent to Which Stock Prices Reflect Future Earnings. Contemporary Accounting Research 19 (1): 117-145. 
Jennings, R. 1987. Unsystematic security price movements, management earnings forecasts, and revisions in consensus analyst earnings forecasts. Journal of Accounting Research 25 (1): 90-110.

Kasznik, R., and B. Lev. 1995. To Warn or Not to Warn: Management Disclosures in the Face of an Earnings Surprise. The Accounting Review 70 (1): 113-34.

Kennedy, J., T. Mitchell, and S.E. Sefcik. 1998. Disclosure of Contingent Environmental Liabilities: Some Unintended Consequences? Journal of Accounting Research 36: 257-277.

King, R., G. Pownall, and G. Waymire. 1990. Expectations Adjustments via Timely Management Forecasts: Review, Synthesis, and Suggestions for Future Research. Journal of Accounting Literature 9: 113-144.

Kordes-de Vaal, J.H. 1996. Intention and the Omission Bias: Omissions Perceived as Non-Decisions. Acta Psychologica. 93: 161-172.

Lambert, R, C. Leuz, and R. Verrecchia, 2007. Accounting Information, Disclosure, and the Cost of Capital, Journal of Accounting Research 45 (2): 385-420.

Leuz, C., and R. Verrecchia. 2000. The Economic Consequences of Increased Disclosure. Journal of Accounting Research 38:91-124.

Landman, J. 1987. Regret and Elation Following Action and Inaction: Affective Responses to Positive Versus Negative Outcomes. Personality and Social Psychology Bulletin 13 (4): 524-536. 
Lang, M. H., and R. J. Lundholm. 2000. Voluntary Disclosure and Equity Offerings: Reducing Information Asymmetry or Hyping the Stock? Contemporary Accounting Research 17 (4): 623-62.

Libby, R., R. Bloomfield, and M. W. Nelson. 2002. Experimental Research in Financial Accounting. Accounting, Organizations and Society 27: 775-810.

Mercer, M. 2005. The Fleeting Effects of Disclosure Forthcomingness on Management's Reporting Credibility. The Accounting Review 80 (2): 723-744.

Miller, G. 2002. Earnings Performance and Discretionary Disclosure. Journal of Accounting Research 40 (1): 173-204.

Nagar, V., D. Nanda, and P. Wysocki. 2003. Discretionary Disclosure and Stock-based Incentives. Journal of Accounting and Economics 34: 283-309.

National Investor Relations Institute (NIRI). 2006. NIRI issues 2006 survey results on earnings guidance practices. Vienna, VA.

Ng, J., I. Tuna, and R. Verdi. 2006. Management Forecasts, Disclosure Quality, and Market Efficiency. Working Paper: The Wharton School, University of Pennsylvania.

Niedermayer, L. Y., and G. Chapman. 2001. Action, Inaction, and Factors Influencing Perceived Decision Making. Journal of Behavioral Decision Making 14: 295308.

Pownall, G., C. Wasley, and G. Waymire. 1993. The Stock Price Effects of Alternative Types of Management Earnings Forecasts. The Accounting Review 68 (4): 896912. 
Prentice, R. A., and J. J. Koehler. 2003. A Normality Bias in Legal Decision Making. Cornell Law Review 88: 583-650.

Rogers, J. L., and P. C. Stocken. 2005. Credibility of Management Forecasts. The Accounting Review 80 (4): 1233-1260.

Securities Industries Association. (SIA). 2005. Equity Ownership in America. New York NY : SIA.

Skinner, D.J. 1994. Why Firms Voluntarily Disclose Bad News. Journal of Accounting Research 32 (1): 38-60.

Spranca, M., E. Mink, and J. Baron. 1991. Omission and Commission in Judgment and Choice. Journal of Experimental Social Psychology 27: 76-105.

Stocken, P. C. 2000. Credibility of Voluntary Disclosure. Rand Journal of Economics 31 (2): $359-74$.

Tan, H.T., R. Libby, and J.E. Hunton. 2002. Analysts' Reactions to Earnings Preannouncement Strategies. Journal of Accounting Research 40(1): 223-246.

Trueman, B. 1986. Why do Managers Voluntarily Issue Earnings Forecasts? Journal of Accounting and Economics: 53-72.

Verrecchia, R. 1983. Discretionary Disclosure. Journal of Accounting and Economics 5: 179-194.

Verrecchia, R. 2001. Essays on Disclosure. Journal of Accounting and Economics 32: $97-$ 180. 
Waymire, G. 1985. Earnings Volatility and Voluntary Management Forecast Disclosure. Journal of Accounting Research 23 (1): 268-295.

Welker, M., 1995. Disclosure Policy, Information Asymmetry and Liquidity in Equity Markets. Contemporary Accounting Research11, 801-828.

Whitener, E., S.Brodt, M. Korsgaard, and J. Werner. 1998. Managers as Initiators of Trust: An Exchange Relationship Framework for Understanding Managerial Trustworthy Behavior. The Academy of Management Review 23 (3): 513-530

Williams, P. A. 1996. The Relation between a Prior Earnings Forecast by Management and Analyst Response to a Current Management Forecast. Accounting Review 71 (1): 103-115.

Zaheer, A, B. McEvily, and V. Perrone. 1998. Does Trust Matter? Exploring the Effects of Interorganizational and Interpersonal Trust on Performance. Organization Science 9(2): 141-15

Zuckerman, G. 2005. CEOs Turn Mum About Projecting Earnings. The Wall Street Journal Online, 03/01/2005, C1. 


\section{Vita}

Shankar Venkataraman was born in Madras, India on March 25, 1969, the son of

Lakshmi and Arunachalam Venkataraman. In May 1989, he graduated with a Bachelor's degree in Commerce from the University of Madras. In May 1991, he received a Post Graduate Diploma in Management from the Indian Institute of Management, Ahmedabad, following which he worked for three years in India in the banking industry. In May 1997, he received a Masters degree in International Management from Thunderbird - The American Graduate School of International Management, Glendale, AZ, following which he worked as an information technology consultant implementing financial applications until 2002. He entered the Graduate School at the University of Texas at Austin in 2002. After completing his degree, he will join the faculty of Georgia Tech College of Management at Atlanta, GA.

Permanent address: 6/29, Gopalakrishna Road, Apt. B1, Malles Yoga Villa, T. Nagar, Chennai 600 017, India.

This dissertation was typed by the author. 